\title{
Multi-period Corporate Short-term Credit Risk Assessment--- A state-dependent stochastic liquidity balance model
}

June 27, 2005

\author{
Hsien-hsing Liao ${ }^{*} \quad$ Tsung-kang Chen ${ }^{* *}$ Tong-Li Chou ${ }^{* * *}$
}

\begin{abstract}
In recent decades, literatures on credit risk measurement evolved dramatically. According to modeling techniques, they can be roughly grouped into two major categories, "accounting-based models" and "market-based models". However, among the above models, few of them develop representative liquidity measure from corporate financial data to evaluate short-term credit risk and further build up a stochastic model based on the liquidity measure. In addition, we can hardly find a model that can generate probability of insolvency and expected liquidity deficiency endogenously and concurrently. Basing upon two significant characteristics of liquidity balance per unit asset (later denoted as LB/A) --"mean-reversion" and "allowing positive and negative values", and the concept of varying coefficient model, the study constructs a "time-dependent stochastic liquidity balance model" to assess multi-period corporate short-term credit risk. It considers the impacts of industrial economic state changes on the structure of a firm's LB/A process (i.e. the parameters of the liquidity balance model) through incorporating information generated from a stochastic industrial economic state model. The liquidity balance model can simulate many LB/A paths and then the LB/A distributions of each future period. With LB/A distribution and the criteria of insolvency (when LB/A is less than zero), we can obtain both the probability of a company's liquidity crisis and the expected liquidity deficiency in future periods. In addition, for outside investors or creditors, this liquidity balance model is readily for them to perform a firm's multi-period short-term credit risk analysis by using only publicly available information of corporate finance and the industrial economic state (i.e. the industrial cyclicality information). The empirical results of this study show preliminarily supports for the effectiveness of the model.
\end{abstract}

Keywords: credit risk, multi-period, liquidity balance

\footnotetext{
*Associate Professor, Department of finance, National Taiwan University, Taiwan, hliao@ntu.edu.tw *** Ph.D Student, Department of finance, National Taiwan University, Taiwan, $\underline{\text { r91723010@ntu.edu.tw }}$ ${ }^{* * *}$ MBA, Department of finance, National Taiwan University, Taiwan
} 


\section{Introduction}

In 2004, the first case of trade receivables securitization, the asset-back commercial paper (ABCP) of World Peace Industrial Co., was issued in Taiwan. Trade-receivable $\mathrm{ABCP}$ provides firms an alternative way for corporate short-term financing. In the United States, ABCP plays an important role in business short-term financing. More than half of business short-term financing is through $\mathrm{ABCP}$ rather than traditional $\mathrm{CP}$. Since the credit of trade receivable $\mathrm{ABCP}$ is based upon the short-term credit of the obligors, the assessment of an obligor's short-term credit risk becomes crucial. However, though many credit risk models have been developed recently, few of them focus on short-term credit risk or liquidity crisis risk of a firm. This study therefore tries to fill this gap and develop an analytical approach to analyze a firm's short-term credit risk.

In recent decades, literatures on credit risk measurement evolved dramatically. According to modeling techniques, they can be roughly grouped into two major categories, "accounting-based models" and "market-based models". The former focuses on selecting appropriate accounting-based measures as predicting variables to do bankruptcy prediction through statistical techniques. This line of literature can be divided into three major types of methodologies: multivariate discriminant analysis (Altman's Z-score, 1968), qualitative response analysis such as probit or logit analysis (Ohlson's O-score, 1980) ${ }^{1}$, and neural networks analysis ${ }^{2}$ (Coates and Fant, 1991-2). The latter, on the other hand, stresses on market information such as stock price or credit rating. They can be roughly classified into "structural-form models" and "reduced-form models". Structural-form models (Merton, 1974; Black and Cox, 1976; Hull and White, 1995) construct the distribution of a firm's asset value and estimate its probability of default and recovery rate. A firm's asset value distribution is derived from equity market value through an option-based theory. Reduce-form models (Litterman and Iben, 1991; Jarrow, Lando and Turnbull, 1997; Duffie, 1998) utilize non-asset-value related market information such as credit rating and recovery rate to estimate and price a firm's credit risk by observable market credit spreads. In sum, market-based models rely on exogenous information instead of a firm's internal financial information and accounting-based models incorporate corporate historical financial data in analysis.

${ }^{1}$ The latest-generation of this model can extend to do multi-period failure prediction by using duration analysis. Duration analysis is to add "default time-related" variables (e.g. age) to be a time-dependent covariate in original one-period model (Shumway, 2001).

${ }_{2}$ Although neural network analysis is computer-based systems trying to mimic the functioning of the human brain by emulating a network if interconnected neurons, it is classified as accounting-based model as a result of its similarity to nonlinear discriminant analysis and the same data employed. 
Though accounting-based models employ corporate financial information to conduct credit analysis, they hardly suggest stochastic modeling to estimate future credit condition. Among those models, few develop a direct liquidity measure from financial accounting data in short-term credit risk analysis ${ }^{3}$. It is also barely found in literature using a stochastic process to model the liquidity measure. In this study, we define a cash flow based measure for corporate liquidity. The liquidity measure, noted as liquidity balance, is defined as the net balance of a firm's liquidity in a short-term period. A concise description of this measure is that it equals to sum of the beginning liquidity reserve (cash and short-term investment) source of liquidity (cash inflow) and drains on liquidity (cash outflow) in a period. To eliminate scale effect we then divide it by total assets in later analysis. A firm's liquidity balance per unit asset less than zero indicates a firm is insolvent and very likely enters into liquidity crisis. Liquidity balance per unit asset is a direct indicator for a firm's capacity to fulfill its obligations. Through our observations of liquidity balance per unit asset, we discover it exhibiting some stochastic characteristics, especially mean-reversion and allowing positive and negative values. It is comprehensible that a firm tends to keep an optimal level of liquidity balance to avoid either entering into insolvency or incurring too much opportunity costs.

To describe multi-period behavior of the liquidity measure, this study builds a stochastic liquidity balance model that can appropriately capture the characteristics of liquidity balance per unit asset. To reflect the changes of state of the industrial economy, the structure (parameters) of the liquidity balance model is time varying according to the changes of industrial state. Following Liao and Chen (2005), we construct a stochastic industrial state model using industrial cyclical indicators as state proxies. We therefore adjust the parameters of the stochastic liquidity balance model by the future states forecasted by the industrial economic state model. The above constructs result in a state-dependent stochastic liquidity balance model. With the liquidity balance model, we can generate a firm's distributions of liquidity balance per unit asset in the future periods. Knowing a firm's liquidity balance distributions and with the criteria of insolvency (when liquidity balance is less than zero), we are able to implement multi-period corporate short-term credit risk analysis including estimating a firm's probability of insolvency and expected liquidity deficiency.

Comparing with the accounting-based models, the current model is different in three aspects. First, we define a cash flow-based liquidity measure that not only directly reflects

\footnotetext{
${ }^{3}$ Emery's Lambda (1982) is an exception. It is defined as [(beginning liquidity reserve plus periodic net cash flow)/uncertainty of periodic net cash flow]. Beginning liquidity reserve is cash adds marketable securities. The general definition of net cash flow is operating cash flow.
} 
a firm's solvency situation but also avoids the problems of earning management as well. Second, the current model is capable of incorporating future industrial information into a firm's expected future solvency. Third, the current model offers a straight criterion for default instead of merely classification through existing samples. Relative to market-based models, the current model is dissimilar in two facets. First, the current model brings into firm-specifically liquidity-related measure as a stochastic variable rather than exogenous information. Second, the current model can directly gauge the probability of a firm's insolvency instead of considering the relationship between debt and asset value or capital structure of a firm in structural-form models.

Overall, the current liquidity balance model has the subsequent features: First, it is a short-term credit risk model that provides a straight criterion for firm's liquidity crisis (when liquidity balance per unit asset is less than zero). Second, it incorporates future industrial information into expected future solvency of a firm. Third, it can be extended to multi-period model. The above three characteristics are rarely simultaneously found in other credit risk models. In addition, using accounting related information and being able to calculated probability of solvency and expected liquidity deficiency, the current liquidity balance model is making a linkage between accounting-based and market-based models. Besides, the current model needs only publicly available information without complicated computation or transformation. The empirical results show that the stochastic liquidity balance model is preliminarily supported.

The rest of the paper is separated into four sections. Section II constructs the state-dependent stochastic liquidity balance model, including discussion on the stochastic characteristics of liquidity balance per unit asset, the basic model setting, and model adjustment with stochastic industrial state model. Section III presents the process of multi-period corporate multi-period short-term credit risk assessment. Section IV shows preliminary empirical analysis to examine effectiveness of the model. Section V demonstrates the application of the model to ABCP pricing. The last section concludes this study.

\section{State-dependent Stochastic Liquidity Balance Model}

In this section, we set up the "state-dependent stochastic liquidity balance model". We first discuss the definition of liquidity and liquidity balance. Then, we explore the characteristics of the defined firm's liquidity balance per unit asset and establish a stochastic model that can appropriately describe its characteristics. Third, we introduce the influence of the changes of future industrial economic state into our liquidity balance models. We then introduce a stochastic model of industrial economic state for adjusting the parameters of 
the liquidity balance model. At last, we show the method of parameters estimation.

\section{Liquidity Balance (LB) and liquidity balance per unit asset (LB/A)}

Generally speaking, liquidity indicates the available and cash inflows that can be used to fulfill required payment obligations. From a broader or long-term perspective, liquidity is the ability to enhance its future cash flow to cover any unforeseen needs or take advantage of any opportunities. Either the traditional or the broader view meets the definition of technically solvency - the ability of paying its obligations as they fall due. More specifically, Emery (1984) suggests six criteria a good liquidity indicator should meet. They are: It should be derived from the probability that the firm will be able to meet its demands for liquidity; It should incorporate an estimate of uncertainty; It should afford management the flexibility to change the time period used in the analysis; It should include only the short-term assets and liabilities that can be readily converted into cash with little loss of value and minimal disruption of daily operations; It should include all potential sources of liquidity (such as line of credit); It should incorporate future cash flow as sources of or drains on liquidity.

Based on these criteria, we develop a liquidity measure, liquidity balance, which equal to the initial liquidity reserve plus periodic net cash flow. That is liquidity is the sum of beginning liquidity reserve adds source of liquidity (cash inflow) and minus drains on liquidity (cash outflow) in a specific period ${ }^{4}$. The definition of liquidity balance is shown in equation (1):

$$
\text { Cash }_{t-1}+\text { SRinvest }_{-1}+C F O_{t}^{M A 4}-D P_{t}+D I_{t}^{*}+\left(S E O_{t}+C F I_{t}\right)^{* *}
$$

Where:

Cash $_{t-1}+$ SRinvest $_{t-1} \quad$ : The beginning cash balance plus short-term investments $\mathrm{CFO}_{t}^{\mathrm{MA4}} \quad$ : Four-quarter moving average operating cash flow in period $\mathrm{t}$.

$D P_{t} \quad$ : Debt payment or net decrease of total debts in period $t$

$D I_{t} \quad:$ Debt issue or net increase of total debts in period $\mathrm{t}$

$\left(S E O_{t}+C F I_{t}\right)$ : Net increase of seasonal equity offering and cash flow from investment in period t.

*: If beginning cash and short-term investment plus four-quarter moving average operating cash flow is less than 0 , cash inflow form financing (debt issue) is included to get the initial LB.

**: If the initial LB is still negative, cash inflow form SEO and investing activities are

${ }^{4}$ In this study, we set the period a quarter due to the constraint of data type. 
then added to calculate the final LB.

The basic idea of liquidity balance is that a firm should keep a positive and stable cash reserve to avoid insolvency ${ }^{5}$. Beginning liquidity reserve comprises cash and short-term investment that can be readily converted into cash with little loss of value and minimal disruption of daily operations. Cash from operation, obtained from a firm's cash flow statement represents net cash flow derived from the firm's recurring activities. ${ }^{6}$ To eliminate effects of credit policies and seasonality, we moving average CFO for every four quarters. In addition, debt payment is considered as a material item of drain on liquidity balance since unable to repay debt is the major cause of firm failures. When the basic liquidity balance--cash and short-term investment plus four-quarter moving average operating cash flow is negative, net increase of debt issue if any are included in the liquidity balance to compensate this deficiency. SEO and cash from investing will be taken into account if the former still cannot fill liquidity gap ${ }^{7}$. The liquidity balance at time $t$ represents the ending liquidity reserve of time $t$.

The current study's liquidity balance shares some similar idea to Emery's Lambda ${ }^{8}$ (Emery 1982). However, the indicator is different from the Lambda in several parts. They are as follows:

1. Liquidity balance consists of more liquidity sources of a firm, including financing cash flow and even investing activities to reflect a firm's possible actions in handling liquidity crunch.

2. Debt payment in the formula is net amount of a variety of financing obligations implying possible line of credit a firm can employ.

3. The composition of liquidity balance conforms to pecking-order theory (or the sequence of financial flexibility). That is, firms use internal operating cash flow first, then seeking external source such as debt and equity. From the sample data, a number of firms did issue additional debt or stocks, or sold investments when running out of cash.

In order to remove scale effect we divide liquidity balance by total assets in following empirical analysis. Therefore, liquidity balance per unit asset is the measure for liquidity

\footnotetext{
${ }^{5}$ For a normally managed firm, the main sources of liquidity should regularly come from operating cash flows. If a firm uses liquidity sources other than operating cash flows too frequently, it may imply a warning signal that the prospect of the firm would be gloomy. This issue can be further explored in future study.

6 Though interest expenses are non-operating related, it is a subtraction item in CFO calculation.

7 Our logic is that in a short-term period, a firm pays it obligations first from its initial liquidity source, operating inflow, and even financing capacity by issuing new debts. Since SEO and cash from investing are usually discretionary and time-consuming, they are included only when the former liquidity capacity is insufficient.

8 Emery's Lambda is [(beginning liquidity reserve plus periodic net cash flow)/uncertainty of periodic net cash flow]. Beginning liquidity reserve is firm's cash balance pluses marketable securities. The general definition of net cash flow is operating cash flow.
} 
analysis in this study. In the following sections, we examine the stochastic characteristics of liquidity balance per unit asset and establish a state-dependent stochastic liquidity balance model to describe its behavior.

\section{Characteristics of liquidity balance per unit asset-normality and mean-reverting}

Through our observations of liquidity balance per unit asset, we discover it exhibits some stochastic characteristics, especially mean-reversion and allowing positive or negative values. Figure 1 to figure 4 display these characteristics. It is sensible that a normally managed firm tends to maintain its liquidity balance per unit asset stable, because an inappropriate high level of liquidity balance per unit asset may cause agency problem and insufficient liquidity balance per unit asset may expose firms to liquidity crisis. In sum, based on the natures of liquidity balance per unit asset we found above, a "mean-reversion stochastic process" seems appropriate to depict liquidity balance per unit asset's characteristics. In addition, by examining historical liquidity balance per unit asset of sample companies, normal distribution for liquidity balance per unit asset is preliminarily supported by statistical results. ${ }^{9}$

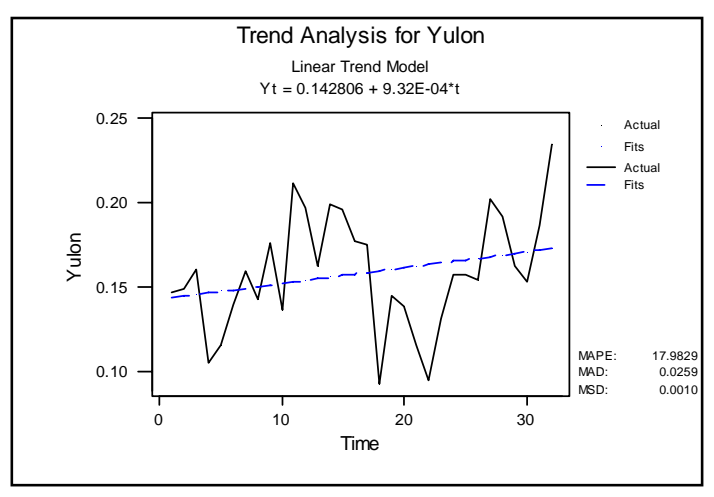

Figure 1 Yulon's liquidity balance per unit asset

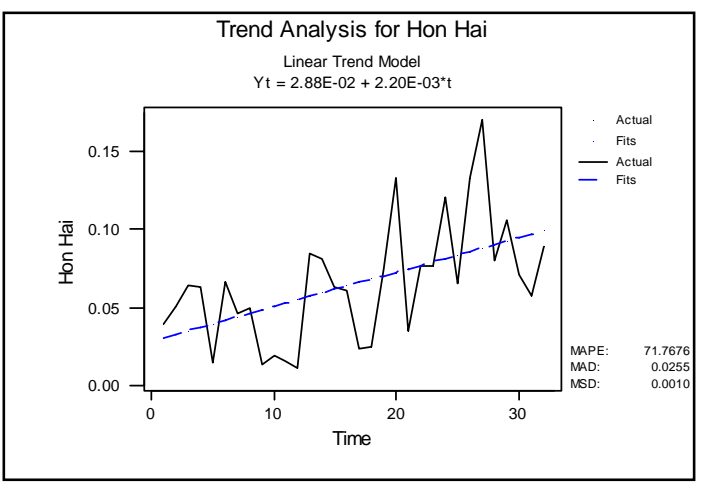

Figure 3 Hon Hai’s liquidity balance per unit asset

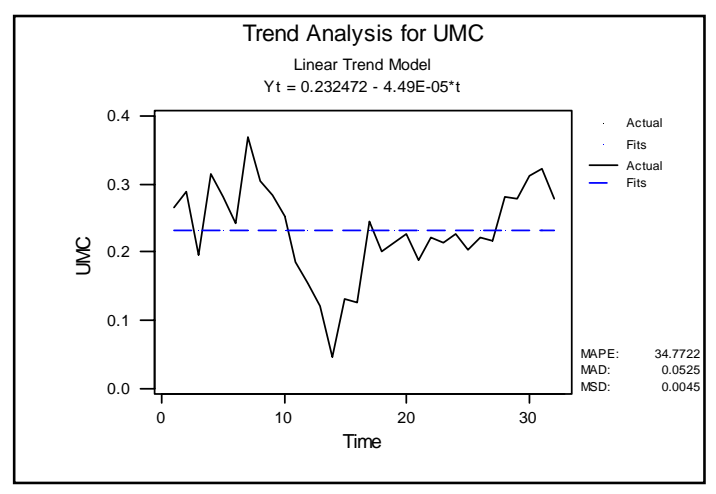

Figure 2 UMC's liquidity balance per unit asset

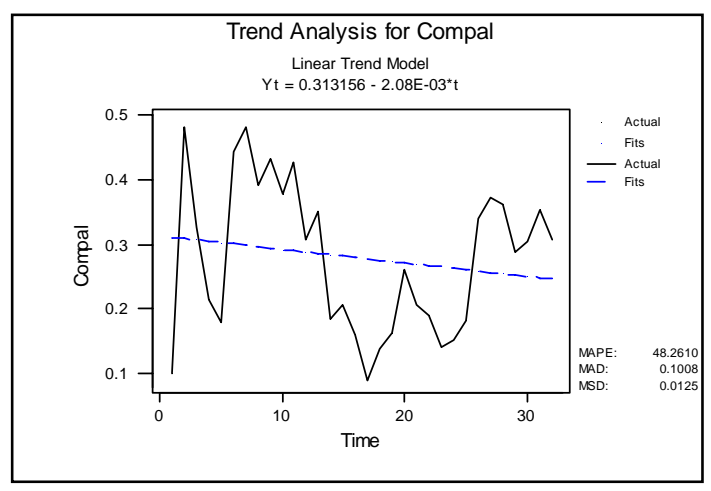

Figure 4 Compal's liquidity balance per unit asset

\footnotetext{
9 The normality test is shown in Appendix I.
} 


\section{Setting of state-dependent stochastic liquidity balance model}

From above discussion, since liquidity balance per unit asset (later denoted as LB/A) is normal-distributed and mean-reverts, we use a mean-reverting Gaussian process to express its future stochastic fluctuation. Moreover, since the major component of a firm's liquidity balance is cash flow from operation, the LB/A must be significantly influenced by changes of industrial economic states. Applying the concept of varying coefficient model ${ }^{10}$, we set the parameters in the stochastic liquidity balance model to be time varying to reflect future economic states. The expected future economic states are obtained from a stochastic industrial economic state model that will be discussed in the following section.

\section{A. Basic model setting}

Following Liao and Chen (2005), we set the "state-dependent stochastic liquidity balance model" as equation (2):

$$
d\left(L B / A_{t}\right)=a(t) \cdot\left[b(t)-L B / A_{t-1}\right] \cdot d t+\sigma(t) \cdot d z, \quad d z=\varepsilon \sqrt{d t}, \quad \varepsilon \sim N(0,1)
$$

where,

$d\left(\mathrm{LB} / \mathrm{A}_{t}\right)$ : liquidity balance per unit asset's term variation (or instantaneous changes in continuous time)

$a(t)$ : liquidity balance per unit asset's mean-reversion speed.

$b(t)$ : liquidity balance per unit asset's long-term average level

$\sigma(t)$ : standard deviation of liquidity balance per unit asset's term variation, namely $\sqrt{\operatorname{Var}\left(d\left(L B / A_{t}\right)\right)}$.

To simplify our model and without loss of generalization, we assume that $a(t)$ in equation (2) is a constant ${ }^{11}$. $a(t)$ stands for long-run mean-reversion speed of a firm's LB/A. $\mathrm{b}(\mathrm{t})$ and $\sigma(t)$ represent long-term average LB/A and standard deviation of LB/A's term changes respectively. These three parameters can be estimated by the MLE (Maximum Likelihood Estimation) method and optimization technique.

\footnotetext{
${ }^{10}$ It is usually applied in time-series sample data. Its characteristic is that it takes the changes of the model's coefficients as one or one more explainable variables in another regression model. And it makes the expected value of the coefficient be decided by several explaining variables.

${ }^{11}$ Actually a $(\mathrm{t})$ will be influenced by the growth trend of individual firm. In this study, the growth trend will reflects in the changes of long-term average levels. To assume a fixed a(t) will not lose the generality of the model.
} 


\section{B. Stochastic industrial state model and parameters' adjustments of the stochastic liquidity balance model}

In this study, two major forces, macroeconomic cycle and industrial maturity, are considered as the basis for adjusting parameters' term-changes in stochastic liquidity balance model. The basic concept of this idea is that industrial economic states will influence a firm's operating performance and its periodic liquidity. The two forces will reflect on the industrial "the growth rate of coincident indictors" or "the growth rate of leading indictors". We incorporate the estimates of the future coincident or leading indictors' growth rate into the stochastic liquidity balance model to grasp the impact of the changes of economic states.

Selecting adequate proxy (industrial coincident or leading indictor) for the industrial economic state of a firm, we build a stochastic industrial economic state model as equation $(3)^{12}$. With this state model, we can estimate the economic states in the future periods.

$$
d\left(\eta_{t}\right)=a_{\eta} \cdot\left[b_{\eta}-\eta_{t-1}\right] \cdot d t+\sigma_{\eta} \cdot d z
$$

where,

$\eta_{t}$ : the growth rate of industrial coincident or leading indictor in time $\mathrm{t}$.

$a_{\eta}$ : the mean-reverting speed of industrial coincident or leading indictor's growth rate

$b_{\eta}$ : the long-term average of industrial coincident or leading indictor's growth rate

$\sigma_{\eta}$ : the standard deviation of the changes of industrial coincident or leading factor's growth rate

The above parameters are both constants and can be estimated by MLE method.

The adjustment of the parameters $b(t)$ and $\sigma(t)$ of the stochastic liquidity balance model in equation (2) are shown as bellow(see appendix III for detailed discussion).

$$
\begin{aligned}
& b(t)=b \cdot\left(1+\psi_{t}^{b}\right) \\
& \sigma(t)=\sigma \cdot\left(1+\psi_{t}^{\sigma}\right)
\end{aligned}
$$

In equations (4) and (5),

$b:$ the long-term average LB/A estimated by MLE method.

$\sigma:$ the standard deviation of LB/A's term changes estimated by MLE method.

$\psi_{t}^{b}$ : the adjustment rate for $\mathrm{b}$ in time period $\mathrm{t}$.

$\psi_{t}^{\sigma}$ :the adjustment rate for $\sigma$ in time period $\mathrm{t}$

12 See the stochastic characteristics of industrial economic state in appendix II. 
When the proxy for industrial economic state is a coincident indicator, then ${ }^{13}$ :

$$
\begin{gathered}
\psi_{t}^{b}=\left(\frac{\alpha_{0}+\alpha_{1} \cdot \omega(t)}{b}\right)^{\frac{1}{t}}-1 \\
\psi_{t}^{\sigma}=\left(\frac{\alpha_{0}+\alpha_{1} \cdot \omega(t)}{b}\right)^{\frac{1}{t}}-\left(\frac{\alpha_{0}+\alpha_{1} \cdot \omega(t-1)}{b}\right)^{\frac{1}{t-1}}
\end{gathered}
$$

In equation (6) and (7),

$\omega(t)$ : the estimated state of industrial economy in future period $t$ from stochastic industrial economic state model.

$\alpha_{0}, \alpha_{1}$ : the intercept and sensitivity of $\mathrm{LB} / \mathrm{A}$ relative to industrial economic state (namely the regression coefficient of $L B / A_{t}=\alpha_{0}+\alpha_{1} \cdot \omega(t)+\varepsilon$, and $L B / A_{t}$ indicating the value of liquidity balance per unit asset in time $t$ ).

From above discussion, under the assumption that the parameters of industrial state model are fixed, our "state-dependent stochastic liquidity balance model" in equation (2) can be rewritten as equation (8):

$$
d\left(L B / A_{t}\right)=a \cdot\left[b \cdot\left(1+\psi_{t}^{b}\right)-L B / A_{t-1}\right] \cdot d t+\sigma \cdot\left(1+\psi_{t}^{\sigma}\right) \cdot d z
$$

\section{Parameters estimation}

In equation (3), all the parameters, $a_{\eta}, b_{\eta}$ and $\sigma_{\eta}$, are estimated by MLE method. We use the estimates from $\mathrm{AR}(1)$ method (Chen, 1996) as initial values for MLE optimization. Because the model of the state of the industrial economy is an O-U process, the conditional density of a specific future industrial economic state is a normal distribution with the mean and variance as follows:

$$
\begin{gathered}
E\left(\eta_{s} \mid \eta_{t}\right)=\eta_{t} \cdot e^{-a_{\eta}(s-t)}+b_{\eta} \cdot\left(1-e^{-a_{\eta}(s-t)}\right) \\
\operatorname{Var}\left(\eta_{s} \mid \eta_{t}\right)=\frac{\sigma_{\eta}{ }^{2}\left[1-e^{-2 a_{\eta}(s-t)}\right]}{2 a_{\eta}}
\end{gathered}
$$

${ }^{13}$ When the proxy for industrial economic state is a leading indicator, then

$$
\psi_{t}^{b}=\left(\frac{\alpha_{0}+\alpha_{1} \cdot \omega(t-1)}{b}\right)^{\frac{1}{t}}-1 \quad \psi_{t}^{\sigma}=\left(\frac{\alpha_{0}+\alpha_{1} \cdot \omega(t-1)}{b}\right)^{\frac{1}{t-1}}-\left(\frac{\alpha_{0}+\alpha_{1} \cdot \omega(t-2)}{b}\right)^{\frac{1}{t-2}}
$$


In equation (9) and (10), $s$ indicates the observed time point in the future.

Moreover, the unconditional distribution of industrial economic state complies with $N\left(b_{\eta}, \frac{\sigma_{\eta}^{2}}{a_{\eta}}\right)$

We therefore introduce a likelihood function of the state variable of the industrial economy as follows:

$$
\begin{gathered}
L\left(a_{\eta}, b_{\eta}, \sigma_{\eta}^{2} ; \eta_{0}, \eta_{t-1}\right)=f\left(\eta_{t=0}\right) \cdot \prod_{t=1}^{T} f\left(\eta_{t} \mid \eta_{t-1}\right) \\
\underset{a_{\eta}, b_{\eta}, \sigma_{\eta}^{2}}{M a x} \ln L\left(a_{\eta}, b_{\eta}, \sigma_{\eta}^{2} ; \eta_{0}, \eta_{t-1}\right)=\ln f\left(\eta_{t=0}\right)+\sum_{t=1}^{T} \ln f\left(\eta_{t} \mid \eta_{t-1}\right)
\end{gathered}
$$

According to equation (12), we can estimate model's parameters by optimization technique and the initial value is estimated by $\operatorname{AR}(1)$ method.

Chen's estimate method $(\operatorname{AR}(1))$ is to rewrite the equation (9) as a discrete autoregressive process for order as follows:

$$
\begin{aligned}
& \eta(s)=\eta(t) \cdot e^{-a_{\eta}(s-t)}+b_{\eta} \cdot\left(1-e^{-a_{\eta}(s-t)}\right)+\xi(s) \\
& \eta_{t+\Delta t}=\eta_{t} \cdot e^{-a_{\eta} \Delta t}+b_{\eta} \cdot\left(1-e^{-a_{\eta} \Delta t}\right)+\xi_{t+\Delta t}
\end{aligned}
$$

Where the error term $\xi$ is normal distributed with mean 0 and variance as described in equation (10). And $\Delta t$ is length of time interval. The AR(1) process allows $\eta_{t}$ to satisfy all three properties of the OU process, i.e., mean, variance, and white noise with normal density. Obtaining this exact form from discretization is essential for simplifying the estimation process of the parameters. Equation (14) can be written as the following regression model:

$$
\eta_{t}=\alpha+\beta \cdot \eta_{t-\Delta t}+e_{t}
$$

where $\alpha=b_{\eta}(1-\beta), \beta=e^{-a_{\eta} \Delta t}$, so all the three parameters can be solved from equation (15).

$$
a_{\eta}=\frac{-L n \beta}{\Delta t} \quad b_{\eta}=\frac{\alpha}{1-\beta_{1}} \quad \sigma_{\eta}^{2}=\frac{2 a_{\eta} \cdot M S E}{1-e^{-2 a_{\eta} \Delta t}}
$$

According to equation (16), we therefore obtain the initial values for the three 
parameters, $a_{\eta}, b_{\eta}$ and $\sigma_{\eta}$, of the stochastic industrial economic state model.

For state-dependent stochastic liquidity balance model, we first employ MLE optimization to estimate its initial parameters $a, b$ and $\sigma$. Then we derive time-varying parameters $b(t)$ and $\sigma(t)$ from equation $(8)$.

\section{Multi-period Corporate Short-term Credit Risk Assessment}

Based upon our model, a multi-period short-term credit risk assessment focuses estimating a firm's multi-period LB/A distribution. With the "state-dependent stochastic liquidity balance model", we can obtain one future LB/A path of a firm by simulating once according to equation (8). Repeating for $\mathrm{N}$ times, we then have a firm's $\mathrm{N}$ paths of LB/A. Through a cross-sectional analysis in each period, we can have the firm's multi-period LB/A distributions. It can be illustrated as figure 5. In figure 5, the LB/A distribution complies with normal distribution founded on the empirical results of goodness-of-fit tests on our sample firms.

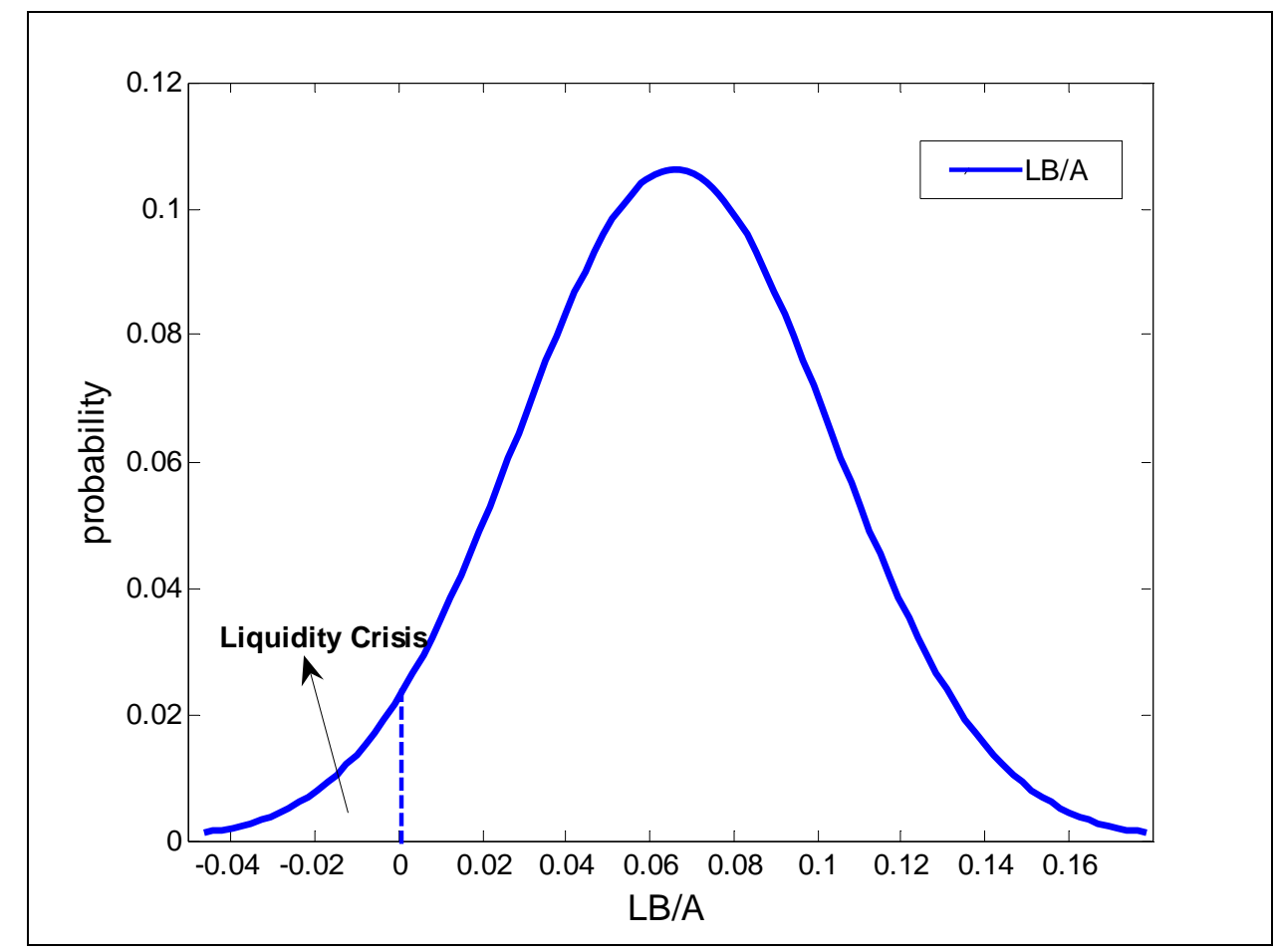

Figure 5. Liquidity Crisis determination method

In this study, a firm is deemed as encountering liquidity crisis if LB/A is less than zero. As a result, we can calculate the probability of insolvency (latter denoted as PIS) and the expected liquidity deficiency (latter denoted as ELD) from the future LB/A's distributions. PIS and ELD can be showed as below: 


$$
\begin{aligned}
& \text { Probability of insolvency }{ }_{t}=\int_{-\infty}^{0} f\left(L B / A_{t}\right) \cdot d\left(L B / A_{t}\right) \\
& \text { Expected liquidity deficiency } t_{t}=\int_{-\infty}^{0}\left(1-L B / A_{t}\right) \cdot f\left(L B / A_{t}\right) \cdot d\left(L B / A_{t}\right)
\end{aligned}
$$

In equation (17), PIS represents for the area of LB/A's distribution conditioning on insolvency (that is LB/A is smaller than zero). In equation (18), ELD is the expected loss per unit asset when LB/A is less than zero in future period. Having these equations, we can implement short-term credit risk assessments for the near future.

In sum, the process of "multi-period corporate short-term credit risk assessment" can be illustrated as figure 6 .

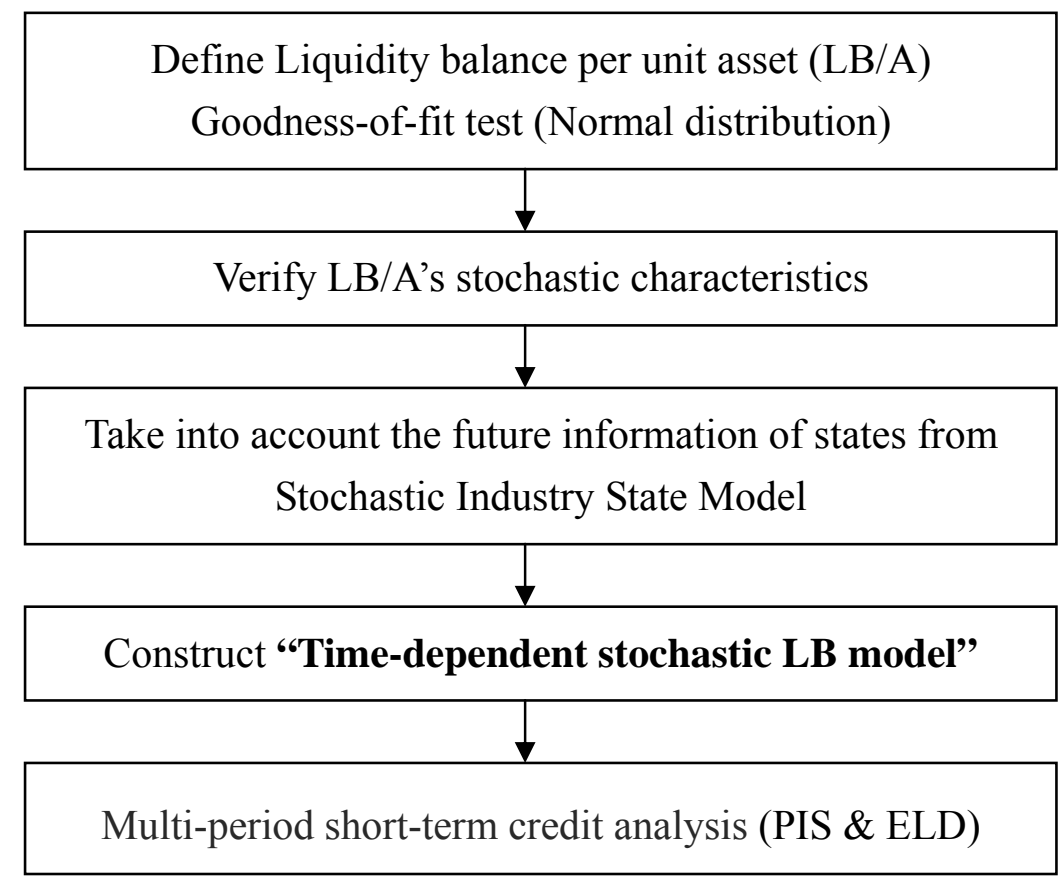

Figure 6. Flow Chart of the Multi-period Corporate Short-term Credit risk Assessment

\section{Empirical Analysis}

In this section, we assess sample firms' short-term credit rating to examine the validity of the "state-dependent stochastic liquidity balance model." In the following, we first introduce our data including sample firms, industrial state proxy and data sources. Second we show parameter estimating results of industrial state model and liquidity balance model. In the last, we present the short-term credit risk assessment results. 


\section{Data}

There are dual selection criteria for sample firms. First, the sample firms need to have 32 quarters historical data to avoid short-term effects of liquidity (credit) management by firms. Second, to verify the validity of our model, the sample firms should incorporate both good and bad firms. As a result, our sample companies are divided into two groups, a normal group and a distressed group. Group I includes 15 normal firms with short-term rating by Taiwan Rating Company (later denoted as TRC). The data period of group I is from 1995 Q1 to 2004 Q3 except FCFC ${ }^{14}$. Group II consists of 22 distressed firms that were classified as having financial distress by TEJ. ${ }^{15}$ For firms in the distress group, the data periods are 32 quarters prior to 1 year before financial distress. The industry distribution of the sample companies is illustrated in table 1. All data source of related financial information, credit rating data, and industrial state is summarized in table 2 . The state proxies for each industry, including coincident and leading indicators, are exhibited in table $3^{16}$.

Table 1. The industrial categories' distribution of empirical sample

\begin{tabular}{|l|c|l|c|}
\hline \multicolumn{1}{|c|}{ Industry } & Numbers of firms & \multicolumn{1}{|c|}{ Industry } & Numbers of firms \\
\hline \hline 1. Steel and metal & 2 & 7. Tourism and department & 2 \\
2. Transportation equipments & 1 & 8. Textile and fiber & 5 \\
3. Plastics & 3 & 9. Foods & 4 \\
4. Cement & 1 & 10. Construction & 6 \\
5. Glass and ceramics & 2 & 11. Wire and cable & 1 \\
6. Information and electronic & 9 & 12. Electro-mechanism & 1 \\
\hline \hline \multicolumn{2}{|c|}{ Total Sample Num. }
\end{tabular}

Table 2. All related empirical data sources

\begin{tabular}{|c|c|c|}
\hline Items & Corporate financial data and ratings & $\begin{array}{c}\text { Industrial economic state (business } \\
\text { cyclical factors) }\end{array}$ \\
\hline Sources & TEJ, TRC website & TEJ, CEPD \\
\hline
\end{tabular}

14 Due to FCFC's structural alteration in industry type from fiber to plastic, its data period is from 1998Q1 to $2004 \mathrm{Q} 3$.

15 The definition of financial distress is set by TEJ. There are 8 sorts of definition of distress in the database. 16 As result of diverse natures of sample firms within a industry, there would be more than one representative state proxy capturing the relationship between firm' liquidity and economic changes. By stepwise regression we abstract adequate proxies shown in table 3 . 
Table 3: The applicable proxies for industrial economic state

\begin{tabular}{|c|c|c|}
\hline Industry & Leading indictors & Coincident indictors \\
\hline 1. Steel and metal & & Shipment Index-Basic Metal \\
\hline \multirow{2}{*}{ 2. Transportation equipments } & & Shipment Value- \\
\hline & & Transportation Equipment \\
\hline 3. Plastics & $\begin{array}{c}\text { Export order } \\
\text {-Rubber and Plastic }\end{array}$ & \\
\hline 4. Cement & & Manufacturing Sales \\
\hline 5. Glass and ceramics & & Shipment Value-Non-Metal Miner \\
\hline \multirow{2}{*}{ 6.Information and electronic } & \multirow{2}{*}{$\begin{array}{l}\text { Export order-Information } \\
\text { and Communication }\end{array}$} & Shipment Index-Electronic Component \\
\hline & & Monitoring Indicator Score \\
\hline 7.Tourism and department & & Monitoring Indicator Score \\
\hline 8.Textile and fiber & & $\begin{array}{l}\text { Shipment Value of Textile } \\
\text { Monitoring Indicator Score }\end{array}$ \\
\hline 9. Foods & & Monitoring Indicator Score \\
\hline 10. Construction & Leading Index & GDP \\
\hline 11.Wire and cable & & Monitoring Indicator Score \\
\hline 12.Electro-mechanism & & Manufacturing Profits Ratio \\
\hline \multicolumn{3}{|c|}{$\begin{array}{l}\text { *. Data period : } 1990 \mathrm{Q} 1-2004 \mathrm{Q} 3 \\
\text { **. The classification of leading indictors or coincident indictors primarily depend on the business } \\
\text { cyclical indictors selected and announced by CEPD (Council of Economic Planning and } \\
\text { Development) }\end{array}$} \\
\hline
\end{tabular}

\section{Parameters estimation of the stochastic models of liquidity balance and industrial economic state}

For the liquidity balance model, we employ MLE optimization to estimate its parameters. Besides, we estimate the coefficients $\left(\alpha_{0}, \alpha_{1}\right)$ of $\mathrm{LB} / \mathrm{A}$ relative to industrial economic state by a linear regression model. The results are illustrated in table A4-1 in appendix IV. To adjust the parameters of the liquidity balance model, we have to estimate the parameters of the stochastic industrial state model. We also employ MLE optimization to estimate its parameters and the results are illustrated as table A5-1 in appendix V.

\section{Empirical results of firm's credit rating}

In this section, we examine the model's effectiveness by assessing sample firms' short-term credit rating using the estimated results of expected probability of insolvency and expected liquidity deficiency from the model. For normal group, we investigate the model's 
validity as follow:

First, we estimate each sample firm's one-year PIS from the liquidity balance model. Next, converting them into corresponding one year long-term rating according to one-year average forward default rates provided by S\&P (1981 2003), we can obtain the model's long-term rating. Since we are doing the short-term credit analysis, we use the correlation table of long- and short-term rating from S\&P and historical transformation of rating firms on TRC website to translate a firm's one-year long-term rating into short-term rating. It should be noted that since the rating assigning benchmark is compiled by US data, the model's long-term rating is not equivalent to local (Taiwan) rating. In practice, a rule of thumb for the rating difference is that Taiwan local ratings are about one rating grade higher than those of global rating because of country credit difference. For example, twA rating is approximately equivalent to global rating BBB. Therefore we upgrade our model's long-term ratings one rating to obtain local long-term ratings. Finally, we compare the model's estimated short-term ratings with actual ones to validate our model.

We show the summarized empirical results in table 4. Since in the "Correlation of Long- and Short-term Rating" table, a long-term rating can be translated into two different short-term ratings. For example, a firm with $\mathrm{A}+$ long-term rating can be converted into short-term rating either A-1+ or A-1. The actual process of short-term rating assignment may depend on judgments by rating agencies basing upon other non-liquidity-related information. To avoid subjective (or selective) bias in the transformation process from long-term rating to short-term rating, we exhibit two sets of empirical analysis results. When a sample firm's long-term rating has more than one corresponding short-term ratings, the first set exhibits the results we assign the firm the rating that are closest to the actual short-term rating of the firm (denoted as best choice situation). The other set contains the results we assign the firm the farthest rating to the current firm short-term rating (denoted as worst choice situation). The results are shown in table 4 .

Regarding the distressed group, since there are no actual ratings to compare with, we can only observe their model rating. Our empirical results show that all sampled distressed firms are $100 \%$ estimated as speculative grade and their model's short-term ratings are all below B grade. The results match their financial reality successfully. Please see table A6-1 in appendix VI for detailed empirical results of rating. 
Table 4: Model's results fit in S\&P forward default rate (One-Year)

\begin{tabular}{|c|c|c|c|}
\hline \multicolumn{4}{|c|}{ Empirical Results of Rating Firms' Short-Term Credit Risk (Sample=15) } \\
\hline & TRC & Best Choice Situation & Worst Choice Situation \\
\hline Total & 15 & 15 & 15 \\
\hline The same rating & 8 & 9 & 8 \\
\hline One-grade rating difference & 5 & 4 & 5 \\
\hline $\begin{array}{l}\text { two or more-grade } \\
\text { rating difference }\end{array}$ & 2 & 2 & 2 \\
\hline Percent correct & $53.3 \%$ & $60.0 \%$ & $53.3 \%$ \\
\hline $\begin{array}{l}\text { Percent within one } \\
\text { rating difference }\end{array}$ & $86.7 \%$ & $86.7 \%$ & $86.7 \%$ \\
\hline \multicolumn{4}{|c|}{$\begin{array}{l}\text { 1. "Correlation of Long- and Short-term Rating" table includes A-1+ grade which is not found on TRC } \\
\text { website. The one-year PIS for A-1+ group is less than } 0.04 \% \text {, which is so tiny that we can take it the } \\
\text { same as A-1 group for comparison convenience. }\end{array}$} \\
\hline \multicolumn{4}{|c|}{$\begin{array}{l}\text { 2. To obtain short-term rating of each sample firm, we first convert each sample firm' PIS and ELGR into } \\
\text { corresponding one year long-term rating according to one-year average forward default rates provided by } \\
\text { S\&P (1981 2003). Then, we get a firm's short-term credit ratings through the "Correlation of Long- } \\
\text { and Short-term Rating" table provided by S\&P website and historical transformation of rating firms on } \\
\text { TRC website. }\end{array}$} \\
\hline \multicolumn{4}{|c|}{$\begin{array}{l}\text { 3. When a sample firm's long-term rating has more than one corresponding short-term ratings, "best choice } \\
\text { situation" indicates that we assign the firm the rating that are closest to the actual short-term rating of the } \\
\text { firm and "worst choice situation" indicates that we assign the firm the farthest rating to the current firm } \\
\text { short-term rating. }\end{array}$} \\
\hline
\end{tabular}

To investigate the robustness of previous empirical results, we employ multinomial logit model and the information generated from our models to classify sample firms into appropriate rating groups ${ }^{17}$. In the following, we explore the rating classification power of the model in several grouping scenarios respectively, including a two-group scenario (investment grade and speculative grade), a three-group scenario (A-1, A-2, and A-3 within investment grade), and a four-group scenario (A-1, A-2, A-3, and speculative grade). The classification results are shown in table 5. As shown in table 5, the model's prediction rate is $91.9 \%, 64.3 \%$ and $78.4 \%$ for two groups, three groups, and four groups correspondingly. It shows that the PIS obtained from the current model performs acceptably in classifying sample firms into appropriate short-term rating groups. The causes of the lower prediction power of three-group scenario could be twofold. First, the sample firms are not enough and may not be appropriate to employ multinomial logistic model. Second, credit rating agencies may consider non-liquidity related information such as debt ratio, ROE, and some

17 We utilize model's PIS, ELD, and PIS-ELD factor as explaining variables. Due to the high correlation of the PIS and ELD variables, we create a new factor, called PIS-ELD that can explain $90.244 \%$ variances. Since all of them have the same prediction power, table 5 only shows PIS. 
other long-term information in determining a firm's short-term rating. It is therefore that one possible way to improve our model is to add some non-liquidity related information in short-term credit analysis.

Table 5: Classification by multinomial logistic model

\begin{tabular}{|c|c|c|c|}
\hline \multicolumn{4}{|c|}{ Empirical Results of Sample Firms' Short-Term Credit Risk } \\
\hline \multirow[t]{2}{*}{ Item } & \multicolumn{3}{|c|}{ Multinomial Logistic Model with PIS as explaining variable } \\
\hline & $\begin{array}{l}\text { Two groups } \\
(\text { sample }=37) \\
\end{array}$ & $\begin{array}{l}\text { Three Groups } \\
\underline{\text { (sample }=14)}\end{array}$ & $\begin{array}{l}\text { Four Groups } \\
\text { (sample=37) }\end{array}$ \\
\hline $\begin{array}{c}\text { Model fitting information } \\
\text { (LR test: chi-square statistics) }\end{array}$ & $12.095 * * *$ & 20.516 & $32.496 * * *$ \\
\hline $\begin{array}{l}\text { Goodness of Fit (Deviance) } \\
\text { (Ho: Multinomial dist.) }\end{array}$ & 12.095 & 18.894 & 30.875 \\
\hline $\begin{array}{l}\text { Pseudo R-square } \\
\text { (Cox and Snell) }\end{array}$ & 0.632 & 0.251 & 0.671 \\
\hline $\begin{array}{r}\text { Variables:(LR tests) } \\
\text {---PIS }\end{array}$ & $49.082 * * *$ & 24.652 & $73.644 * * *$ \\
\hline Precise prediction rate & $91.9 \%$ & $64.3 \%$ & $78.4 \%$ \\
\hline
\end{tabular}

In short-term credit analysis, the most important objective is to differentiate investment grade (good) firms from speculative (bad) firms. In rating classification, we therefore care more on type II error than on type I error. That is, classifying a "bad" firm as a "good" one causes much more cost than misclassifying a "good" firm as a "bad" one. Table 6 shows that type II error is quite low in the two-group scenario. In table 6, only one firm out of 23 bad ones is regarded as a good company. All in all, from table 4 to 6 , the empirical results seem providing preliminarily support for our model's effectiveness.

Table 6: Prediction Table of Two-Group-Classification

\begin{tabular}{|c|ccc|}
\hline \multicolumn{4}{|c|}{ Classification } \\
\hline \multirow{2}{*}{ Observed } & \multicolumn{4}{c|}{ Predicted } \\
\cline { 2 - 4 } & Good & Bad & Percent Correct \\
\hline Good & 12 & 2 & 85.71 \\
Bad & 1 & 22 & 95.65 \\
\hline \hline Overall Percentage & 35.14 & 64.86 & 91.89 \\
\hline
\end{tabular}




\section{Model's Application in Pricing ABCP}

The above developed state-dependent stochastic liquidity balance model can be applied to gauge credit risk of short-term-corporate-credit-related derivatives such as asset-backed commercial paper $(\mathrm{ABCP})$. Our model is especially useful in the valuation of this revolving-type instrument since it can provide forward probability of insolvency (PIS) and expected liquidity deficiency (ELD) of an obligor (firm). We use UMC as an example and describe its multi-period distributions in figure $7 \& 8$.

The following is a more detailed discussion about applying our model to price a trade-receivable ABCP with single-sponsor-multi-obligors structure. Here we simplify the relationship between obligors, assuming they are not cross-collateralized and do not have cross-default contracts. Though most of sample firms' LB/A are normal-distributed by the normality test, the joint probability density function of normal-distributed LB/A is not guaranteed to comply with multivariate normal distribution. In order to simplify the example, multi-obligors' $\mathrm{LB} / \mathrm{A}$ is assumed to be multivariate normal-distributed. Last but not least important, we have to adjust LB/A to exactly evaluate ELD of the portfolio. It should be noted that LB/A indicates the deficiency amount per unit asset given insolvency rather than per unit payment obligation. If we apply LB/A straightly, there is an under-estimate bias for ELD assessment. Therefore, we let LB/A divided by payment obligation per unit asset $(\mathrm{OB} / \mathrm{A})$ to get liquidity balance per unit obligation $(\mathrm{LB} / \mathrm{OB})^{18}$. From our observations of historical data, $\mathrm{OB} / \mathrm{A}$ is mean-reverting and maintains a stable level. Since OB/A is similar to debt ratio (total debts divided by total assets), the phenomenon seems complying with optimal capital structure theory. Based on the mean-reverting characteristic, $\mathrm{OB} / \mathrm{A}$ is simplified to be a constant (historical mean level) so that $\mathrm{LB} / \mathrm{OB}$ is still normal-distributed.

\footnotetext{
18 The definition of obligation consists of all the drains (cash outflow) on liquidity. We employ accounting direct method for cash flow statement to separate operating outflow from net operating cash flow. Approximately, one can use debt ratio as proxy for $\mathrm{OB} / \mathrm{A}$ to reduce the complexity of the calculation.
} 


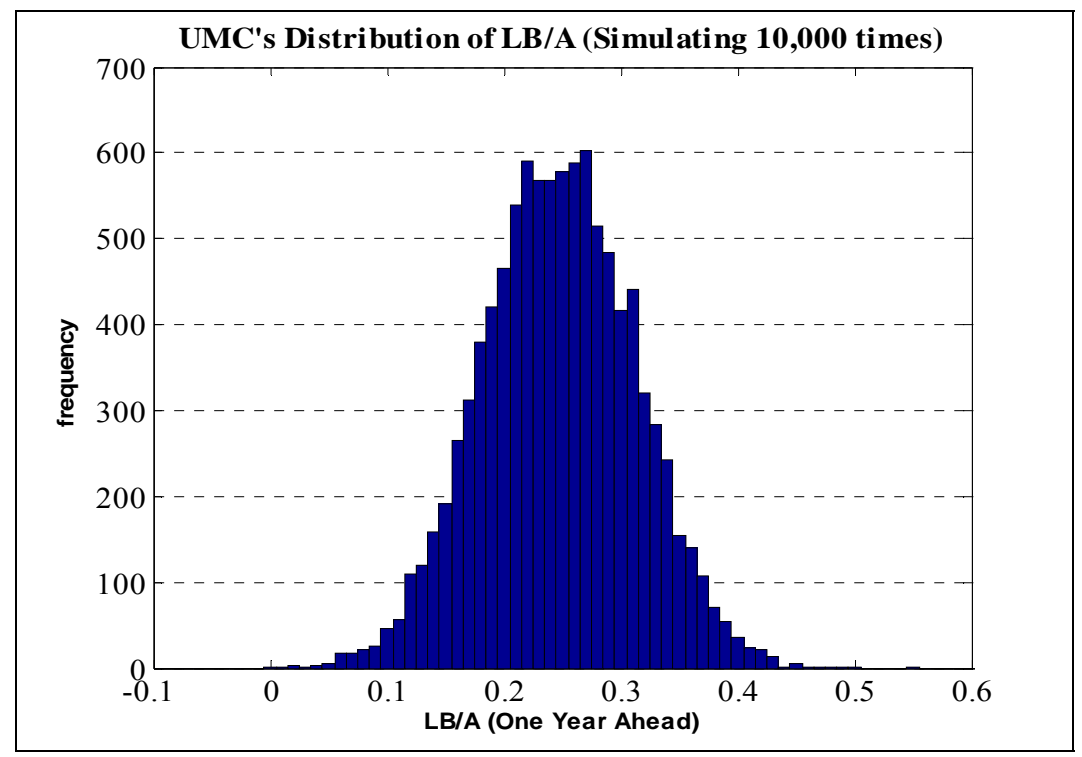

Figure 7. UMC's One-Year Distribution of LB/A

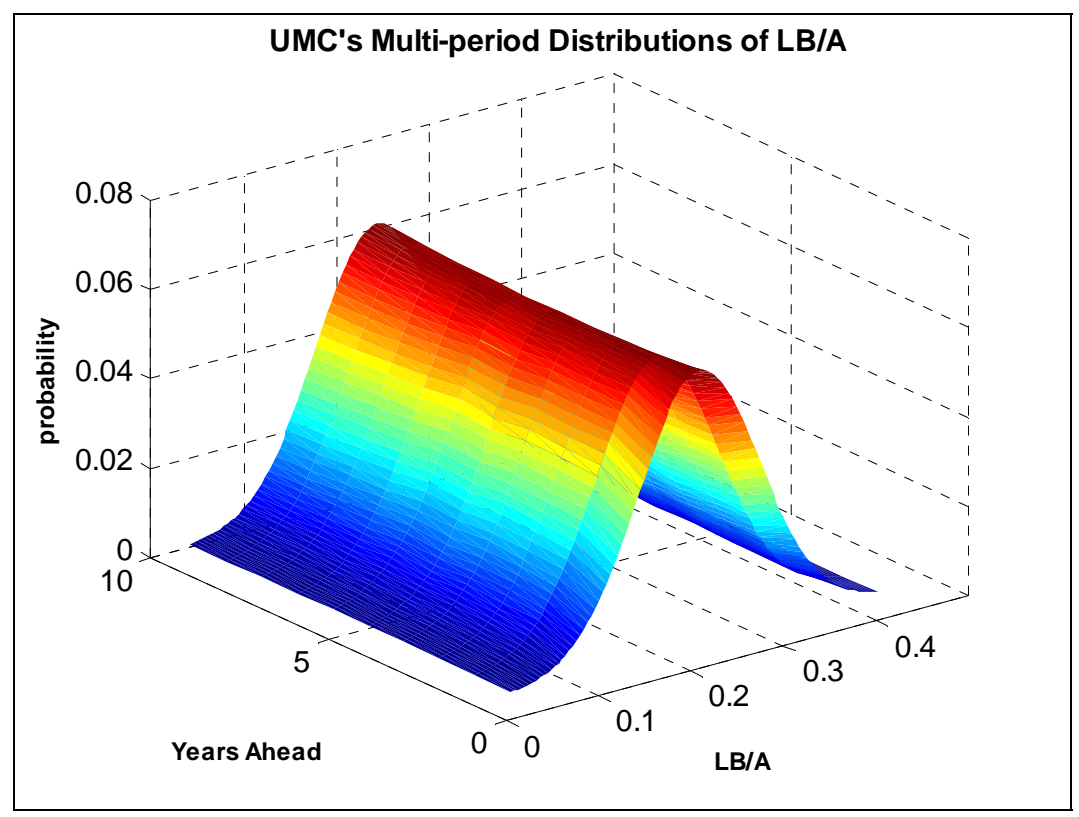

Figure 8. UMC's Multi-period Distributions of LB/A

Under the above assumptions, by transforming LB/A into LB/OB, a portfolio's probability of insolvency (PIS) can be estimated by considering correlation matrix. The inference is as follows.

$\mathrm{LB} / \mathrm{OB}$ of the multi-obligors portfolio follows $n$-dimensional ( $n$-firms) multivariate normal distribution with mean vector $\mu$ and covariance matrix $\Sigma$ as $N_{n}(\mu, \Sigma)$. If $\Sigma$ is positive definite, the probability density function for LB/OB is shown as equation (19): 


$$
f_{n}\left(\frac{L B}{O B}\right)=\frac{\exp \left(-\frac{1}{2}\left(\frac{L B}{O B}-\mu\right)^{\prime} \Sigma^{-1}\left(\frac{L B}{O B}-\mu\right)\right)}{\sqrt{(2 \pi)^{n} \cdot|\Sigma|}}
$$

According to equation (19), the PIS and ELD of the multi-obligors portfolio can be written as equation (20) and (21).

$$
P I S_{t}^{n}=1-\int_{0}^{\infty} \int_{0}^{\infty} \ldots \int_{0}^{\infty} \int_{0}^{\infty} f_{n}\left(\frac{L B}{O B}\right) \cdot d\left(\frac{L B}{O B_{1}}\right) \ldots d\left(\frac{L B}{O B_{n}}\right)
$$

In equation (20), the portfolio's PIS cover these situations for one firm's insolvency, two firms' insolvency,......, $\mathrm{N}$ firms' simultaneous insolvency; namely, PIS is one minus the probability of all the firms' being solvent coincidently.

$$
E L D_{t}^{n}=\sum_{k=1}^{n} \sum_{t=1}^{C_{t}^{n}}\left(\prod_{j=n-i}^{0} \int_{0}^{\infty}\left(\prod_{i=1}^{n} \int_{-\infty}^{0}\left(\prod_{i=1}^{k}\left(0-\frac{L B}{O B}\right) \cdot f_{n}\left(\frac{L B}{O B}\right)\right) \prod_{i=1}^{n} d\left(\frac{L B}{O B}\right)\right) \prod_{j=n-i}^{0} d\left(\frac{L B}{O B}{ }_{j}\right)\right)
$$

In equation (21), the portfolio's ELD can be calculated by considering all the insolvency situations (one firm's insolvency,..., $\mathrm{N}$ firms' insolvency). Here $\mathrm{k}$ refers to the $\mathrm{k}$-th situation and $\mathrm{t}$ stands for the $\mathrm{t}$-th firm in $\mathrm{k}$-th situation.

According to the above concepts, we demonstrate a simple example of pricing a trade-receivable ABCP with single-sponsor-and-multi-obligors structure in the following paragraphs. The scenario is set as follows:

Provided an X firm issues a 3-month $\mathrm{ABCP}$ and its asset pool includes trade receivables from three obligors (shown in table 7). To price the ABCP, it is essential to evaluate the three obligors' short-term credit risk. With the information of probability of insolvency (PIS) and expected liquidity deficiency (ELD) obtained from our model, we can employ the concept of J-T model (Jarrow and Turnbull, 1995) to determine the ABCP's theoretical price by considering both interest risk and obligors' short-term credit risk.

Table 7 introduces three obligors in the asset pool and Table 8 shows correlation of these obligors' LB/A. For simplification, the maturity and maturity date of ABCP and trade receivables of three obligors are all the same. Table 9 demonstrates differently-weighted portfolio's forward PIS \& ELD in the next four quarters. The results of the 3-month ABCP's pricing are illustrated in table 10. Repeating steps in table 10 based on forward PIS and ELD of portfolio, one can evaluate revolving ABCP without difficulty. 
Table 7. The Basic Information of the Assumed ABCP

\begin{tabular}{|c|c|c|c|}
\hline Components & $\mathrm{CSC}$ & UMC & Yageo \\
\hline Industry & Steel and Metal & $\begin{array}{c}\text { Information and } \\
\text { electronics }\end{array}$ & $\begin{array}{c}\text { Information and } \\
\text { electronics }\end{array}$ \\
\hline Long-term rating & twAAA & twAA & twBB + \\
\hline Short-term rating & twA-1 & twA-1 & twB \\
\hline Issue date & \multicolumn{3}{|c|}{$2005 / 4 / 1$} \\
\hline Maturity date & \multicolumn{3}{|c|}{$2005 / 7 / 1$} \\
\hline
\end{tabular}

Table 8. Historical Correlation of Obligors' LB/A

\begin{tabular}{|c|ccc|}
\hline & CSC & UMC & Yageo \\
\hline CSC & 1.0000 & -0.0054 & -0.6242 \\
UMC & -0.0054 & 1.0000 & 0.3220 \\
Yageo & -0.6242 & 0.3220 & 1.0000 \\
\hline
\end{tabular}

Table 9. Portfolio's Forward PIS and ELD

\begin{tabular}{|c|c|c|c|c|}
\hline \multicolumn{5}{|c|}{ Portfolio's PIS \& ELD in the following four quarters } \\
\hline \hline Quarter & Portfolio PIS & $\begin{array}{c}\text { Portfolio ELD } \\
\text { (equally-weighted) }\end{array}$ & $\begin{array}{c}\text { Portfolio ELD } \\
(40 \%-40 \%-20 \%)\end{array}$ & $\begin{array}{c}\text { Portfolio ELD } \\
(20 \%-20 \%-60 \%)\end{array}$ \\
\hline \hline \multicolumn{5}{|c|}{ Panel A. Portfolio Spot PIS \& ELGR } \\
2 & $13.43 \%$ & $0.7006 \%$ & $0.4206 \%$ & $1.2605 \%$ \\
3 & $12.99 \%$ & $0.6569 \%$ & $0.3946 \%$ & $1.1817 \%$ \\
4 & $12.82 \%$ & $0.6223 \%$ & $0.3793 \%$ & $1.1357 \%$ \\
\hline \hline
\end{tabular}

Table 10. Theoretical Price of the Assumed ABCP

\begin{tabular}{|c|c|c|c|c|c|c|c|}
\hline \multicolumn{7}{|c|}{ ABCP Pricing } \\
\hline Portfolio weight & Maturity & Yield & $\mathrm{d}(0, \mathrm{t})$ & ERRGI & $\mathrm{V}(0, \mathrm{t})$ & Par & Theoretical Price \\
\hline \hline \multicolumn{7}{|c|}{ 3-month ABCP Portfolio } & \\
\hline \hline $\begin{array}{l}\text { equally-weighted } \\
\mathbf{4 0 \% - 4 0 \% - ~ 2 0 \% ~}\end{array}$ & $2005 / 7 / 1$ & 0.0102 & 0.9899 & 0.9958 & 0.9857 & 100 & $\mathbf{9 8 . 5 6 8 6}$ \\
$\mathbf{2 0 \% - 2 0 \% - 6 0 \%}$ & & & & 0.9874 & 0.9774 & & $\mathbf{9 7 . 7 3 7 3}$ \\
\hline
\end{tabular}


1. Yield: 90-day rate without short-term credit risk. Due to lack of data, we calculate 90-day rate of treasury bill from 183-day and 30-day TB rate by interpolation.

2. $\mathrm{d}(0, \mathrm{t})$ : discounted factor of ABCP without short-term credit risk.

3. ERRGI: expected recovery rate given insolvency. It equals to 1-ELD.

4. $\mathrm{V}(0, \mathrm{t})$ :the value of $\mathrm{ABCP}$ per face amount with short-term credit risk

5. Par: par value of $\mathrm{ABCP}$

6. Theoretical Price: portfolio's par value times $\mathrm{V}(0, \mathrm{t})$

\section{Summary and Conclusion}

Among the traditional "accounting-based" and "market-based" credit models, few of them develop representative liquidity measure from corporate financial data and based upon it to build up a stochastic model based to assess a firm's short-term credit risk. It is also hardly to find a model that generate probability of insolvency and expected liquidity deficiency endogenously and concurrently.

"state-dependent stochastic liquidity balance model" constructed in this study builds a bridge between "accounting-based models" and "market-based models" and establishes a systematic measuring process of multi-period corporate short-term credit risk assessments. It can provide a firm's multi-period probability of insolvency (PIS) and expected liquidity deficiency (ELD) endogenously and concurrently. In addition, for outside investors or creditors, this liquidity balance model is readily for them to perform a firm's multi-period short-term credit risk analysis by using only publicly available information of corporate finance and the industrial economic state (i.e. the industrial cyclicality information). The empirical results of this study show preliminarily supports for the effectiveness of the model. 


\section{Reference}

Altman, E. I., 1968, "Financial Ratios, Discriminant Analysis, and the Prediction of Corporate Bankruptcy", Journal of Finance 23, 589-609.

Altman, E. I., Anthony Saunders, 1998, “Credit Risk Measurement: Development over the Last 20 Years", Journal of Banking and Finance, 21, 1721-1742.

Beaver, B., 1966, "Financial Ratios as Predictors of Failure", Empirical Research in Accounting: Selected Studies, Supplment to Journal of Accounting Research Autumn, $91-101$.

Black, Fischer and John C. Cox, 1976, "Valuing Corporate Securities: Some Effects of Bond Indenture Provisions", Journal of Finance, 31, 351-367.

Caouette, John B., Edward I. Altman, and Paul Narayanan, 1998, Managing Credit Risk, John Wiley \& Sons, Inc.

Chen, Ren-raw, 1996, Understanding and Managing Interest Rate Risks, World Scientific, chapter 5 .

Chen, Tsung-Kang and Hsien-Hsing Liao, 2004, “A Cash Flow Based Multi-period Credit Risk Model", Conference paper, A Paper Presented to the 12th Conference on the Theories and Practices of Securities and Financial Markets.

Coates, P. and L. Fant, 1991-2, “A Neural Network Approach to Forecasting Financial Distress", The Journal of Business Forecasting, Winter, 9-12.

Dambolena, Ismael G., and Joel M. Shulman, 1988, “A Primary Rule For Detecting Bankruptcy: Watch The Cash”, Financial Analysts Journal, Sep/Oct, 74-78.

Duffie, Darrell, 1998, “Defaultable Term Structure Models with Fractional Recovery of Par”, Graduate School of Business, Stanford University.

Emery, Gary W., 1984, "Measuring Short-term Liquidity”, Journal of Cash Management, July/August.

Emery, Gary W. and Kenneth O. Cogger, 1982, “The Measurement of Liquidity”, Journal of Accounting Research, 20 (2), 290-303.

Emery, Gary W. and R. Lyons, 1991, “The Lambda Index: Beyond the Current Ratio", Business Credit, Nov/Dec, 22-23.

Gallinger, George W. and P. Basil Healey, 1992, Liquidity Analysis and Management, 
Addison-Wesley Publishing Company.

Gombola, Michael J., Haskins, Mark E., Ketz, J. Edward, Williams, David D., 1987, “Cash Flow in Bankruptcy Prediction", Financial Management, Winter, 55-65.

Hull, J. and A. White, 1995, "The Impact of Default Risk on the Prices of Options and Other Derivative Securities", Journal of Banking and Finance, 19, 299-322.

Jarrow, Robert A., David Lando and Stuart M. Turnbull, 1997, "A Markov Model for the Term Structure of Credit Risk Spreads", The Review of Financial Studies, 10 (1), $481-523$. Jarrow, Robert A. and Stuart M. Turnbull, 1995, "Pricing Derivatives on Financial Securities Subject to Credit Risk", Journal of Finance, 50, 53-86.

Kallberg, Jarl G. and Kenneth L. Parkinson, 1993, Corporate Liquidity: Management and Measurement, Richard D. Irwin.

Lando, David, 2004, Credit Risk Modeling, Princeton University Press.

Liao, Hsien-Hsing and Tsung-Kang Chen, 2005, “A Multi-period Corporate Short-term Credit Risk Model”, Review of Financial Risk Management, 1 (1), 61-86.

Litterman, Robert and T. Iben, 1991, "Corporate Bond Valuation and the Term Structure of Credit Spreads", Financial Analysts Journal, Spring, 52-64.

Merton, Robert C., 1974, “On the Pricing of Corporate Debt: The Risk Structure of Interest Rates", Journal of Finance, 2, 449-471.

Mossman, Charles E., Geoffery G Bell, L Mick Swartz, and Harry Turtle, 1998, “An empirical comparison of bankruptcy models", The Financial Review, 33, 35-54.

McQuown J.A., 1997, "Market versus Accounting-Based Measures of Default Risk”, in I. Nelken, edited by, Option Embedded Bonds, Irwin Professional Publishing, Chicago.

Ohlson, J., 1980, "Financial Ratios and the Probabilistic Prediction of Bankruptcy”, Journal of Accounting Research, 19, 109-131.

Ralph B. D’Agostino and Michael A. Stephens, 1986, “Goodness-of-fit techniques”.

Shumway, T., 2001, "Forecasting Bankruptcy More Accurately: A Simple Hazard Model", Journal of Business, 74, 101-124.

Wilson, T., 1997a, Portfolio Credit Risk, I. RISK 10, September, 111-117.

Wilson, T.,1997b, Portfolio Credit Risk, I. RISK 10, October, 56-61. 


\section{Appendix I. Goodness-of-fit tests for firms’ liquidity balance per unit asset}

In order to test liquidity balance per unit asset's actual distribution, we firstly implement goodness-of-fit tests on liquidity balance per unit asset. The normality test of liquidity balance per unit asset is preliminarily supported by statistical results. The test results are shown in table A1-1. In table A1-1, the results show that $64.86 \%$ sample companies don't significantly reject the null hypothesis of normality when significant level is $0.01^{19}$.

Table A1-1. Normality tests for liquidity balance per unit asset

\begin{tabular}{|c|c|c|c|}
\hline \multicolumn{4}{|c|}{ Short-term rating sample $($ Total $=37)$} \\
\hline Ticker & Normality test & Ticker & Normality test \\
\hline FCFC & $23.88^{*}$ & PEWC & 2.66 \\
\hline FPC & $19.80^{*}$ & Ensure & $16.52 *$ \\
\hline NPC & $15.32 *$ & Chou Chin & $26.93 *$ \\
\hline $\mathrm{ACC}$ & 0.50 & Yuan Yi & 0.95 \\
\hline $\mathrm{CSC}$ & 3.52 & TI & $14 *$ \\
\hline Yulon & 0.00 & SJI & $23.71^{*}$ \\
\hline TSMC & 8.19 & Hualon & 5.67 \\
\hline UMC & 3.04 & CST & 4.15 \\
\hline Hon Hai & 4.39 & Maxim & $34.66^{*}$ \\
\hline Compal & 5.42 & Yu Foong & 6.47 \\
\hline Benq & 7.3 & Shin Yih & 5.5 \\
\hline Yageo & $10.14^{*}$ & Pao Shiang & 8.73 \\
\hline $\mathrm{CMC}$ & 4.17 & Bao-Chen & 4.82 \\
\hline Long Bon & $13.39^{*}$ & Lin San Hao & $18.36^{*}$ \\
\hline CRE & 8,86 & $\begin{array}{l}\text { Pacific } \\
\text { Construction }\end{array}$ & 3.48 \\
\hline Imperial Hotel 7 & 0.12 & ADI & 6.54 \\
\hline TID. & 0.08 & Megamedia & 4.59 \\
\hline KPT & $16.38^{*}$ & Ornatube & $10.19^{*}$ \\
\hline Must & 6.63 & & \\
\hline
\end{tabular}

19 When $\alpha=0.05,0.04,0.03$, and 0.02 , the proportion that sample companies don't significantly reject the null hypothesis of normality is $45.95 \%, 45.95 \%, 54.05 \%$, and $56.76 \%$ respectively. 


\section{Appendix II. The stochastic characteristics of industrial economic state}

In this study, we use the change rate of four-quarter-moving-average coincident or leading indicators of each industry to be the proxies for industrial economic state. The data source is TEJ and the sample period is from 1990 to 2004, and the data type is quarterly. Industries included are steel and metal, transportation equipments, cement, plastics, information and electronics, constructions, foods, textile and fibers, glass and ceramics, tourism and department, wire and cable, and electro-mechanism. Historical trend of each industrial economic state factor is illustrated in the following figures. From these figures, we can observe that there exists the phenomenon of mean-reversion in all industries. Table A2-1 also shows a majority of state proxy's growth rate don't significantly reject the null hypothesis of normality when significant level is $0.01^{20}$. It is appropriate to use mean-reversion Gaussian process to describe the behavior of the state of industrial economy.

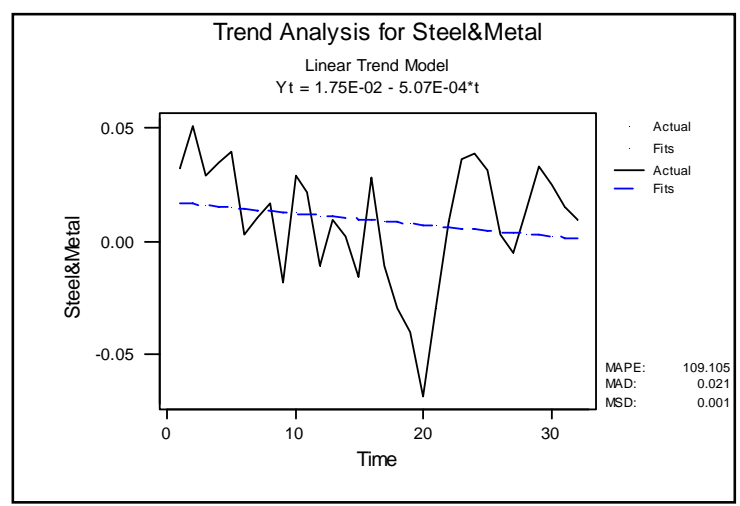

Figure A2-1 state's change rate of steel \& metal industry

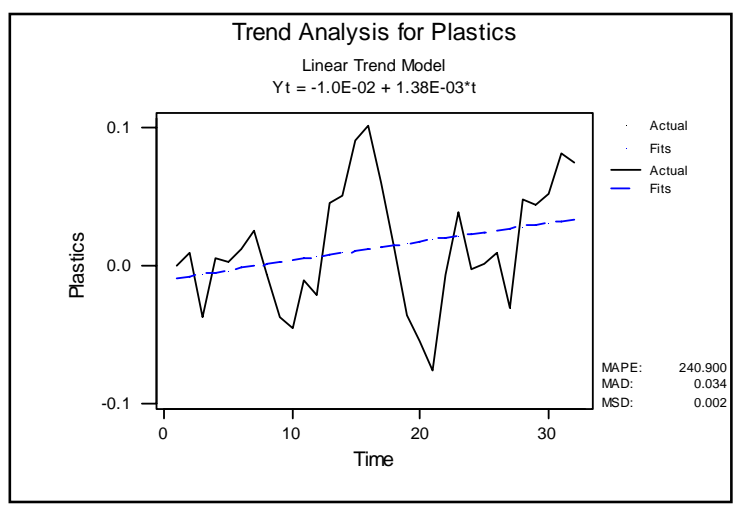

Figure A2-3 state's change rate of plastic industry

${ }^{20}$ The test result is the same when $\alpha=0.05$.

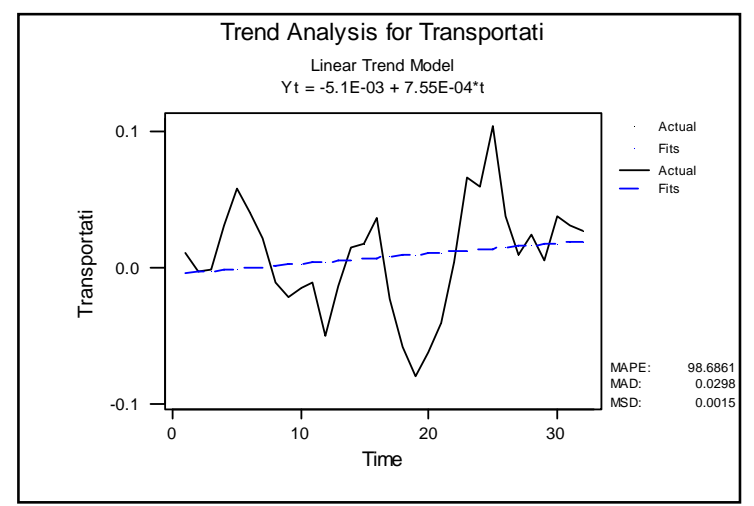

Figure A2-2 state's change rate of transportation equipment industry

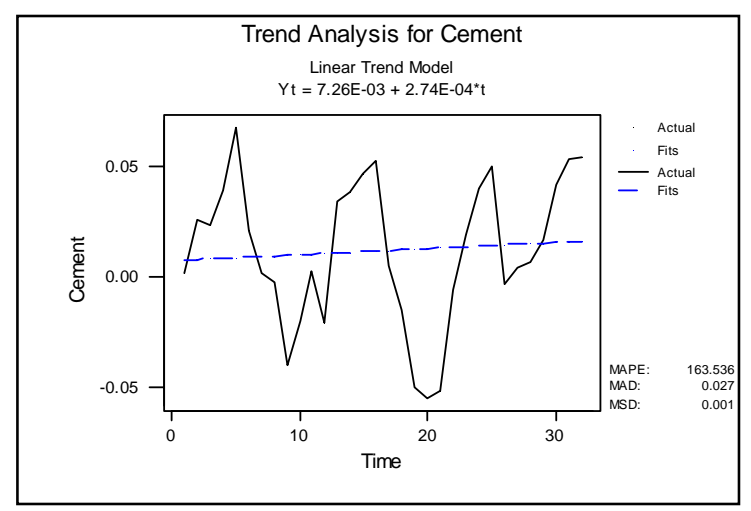

Figure A2-4 state's change rate of cement industry 


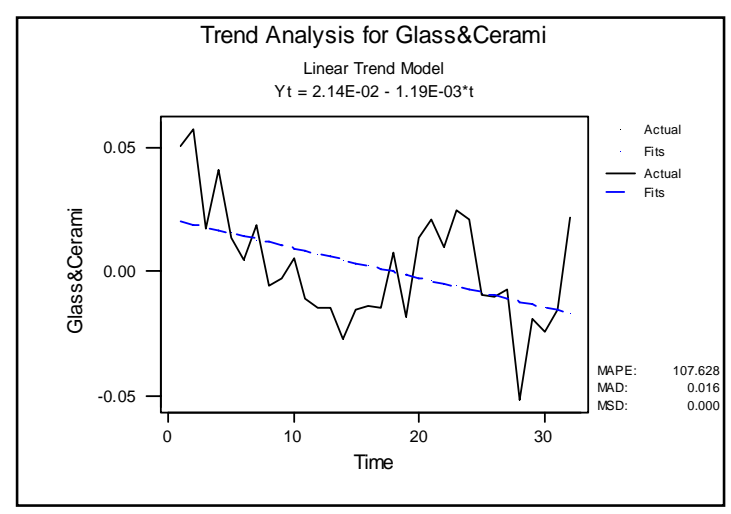

Figure A2-5 state's change rate of glass \& ceramics industry

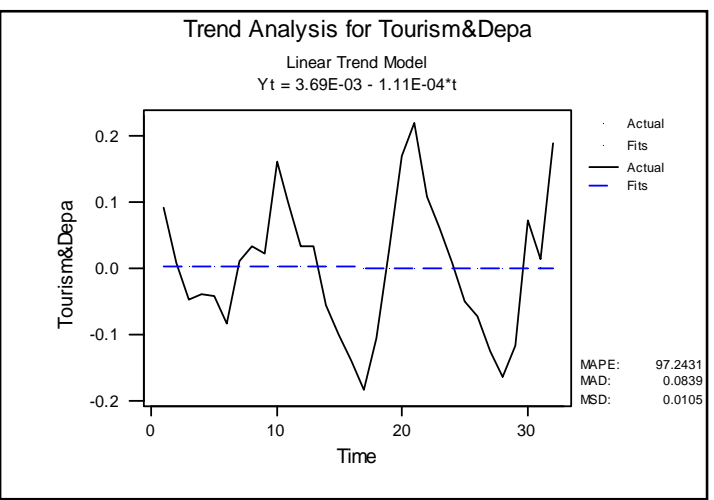

Figure A2-7 state's change rate of tourism $\&$ department industry

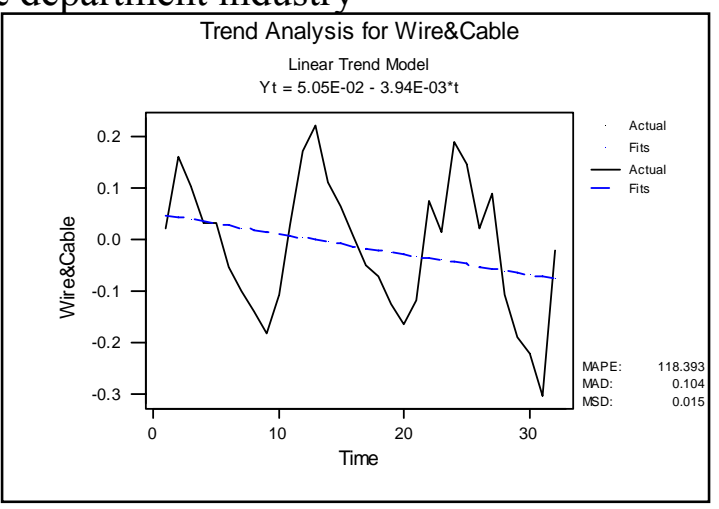

Figure A2-9 state's change rate of wire \& cable industry

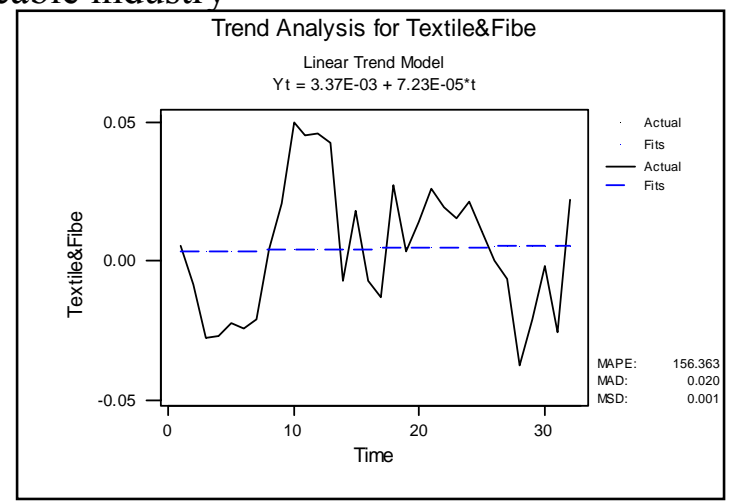

Figure A2-11 state's change rate of textile $\&$ fibers industry

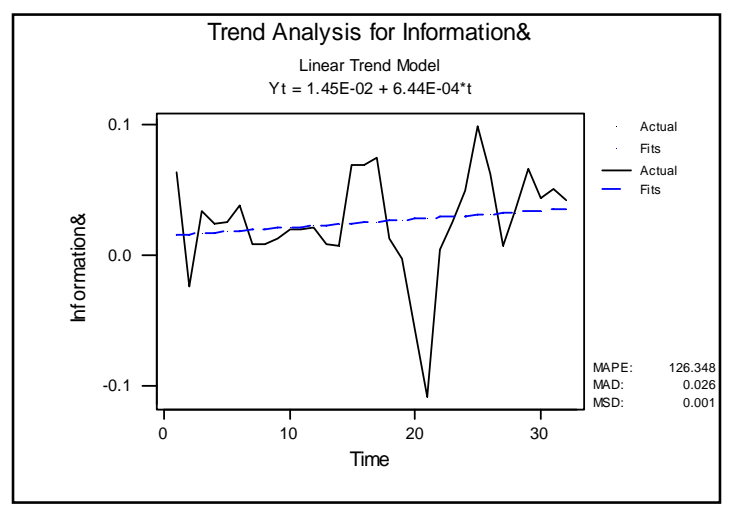

Figure A2-6 state's change rate of information \& electronics industry

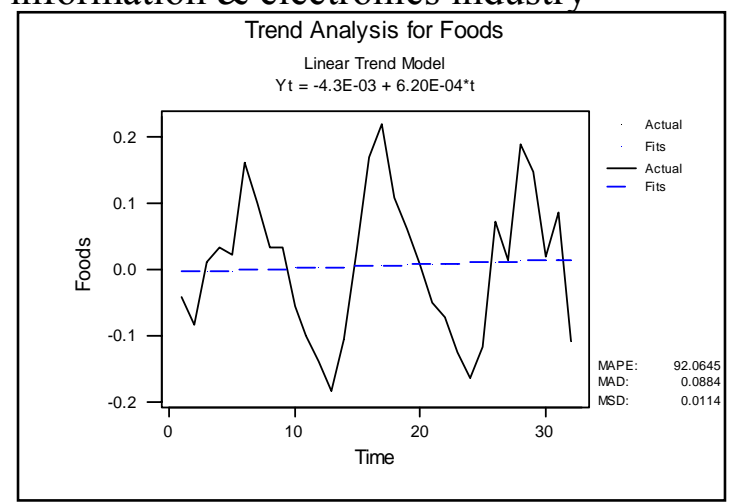

Figure A2-8 state's change rate of foods industry

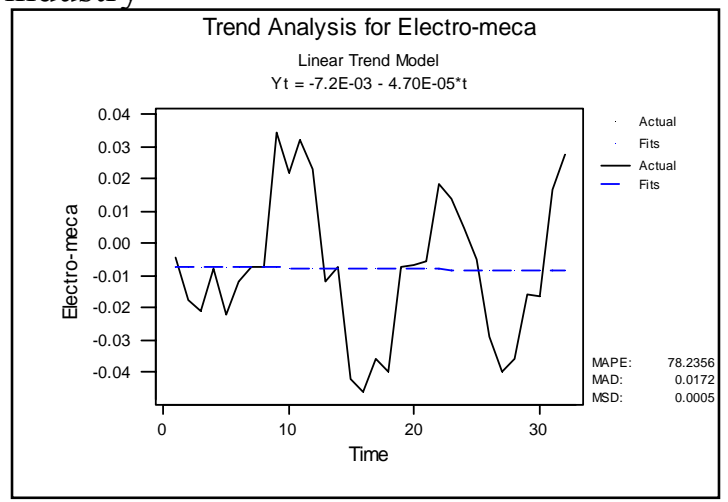

Figure A2-10 state's change rate of electro-mechanism industry

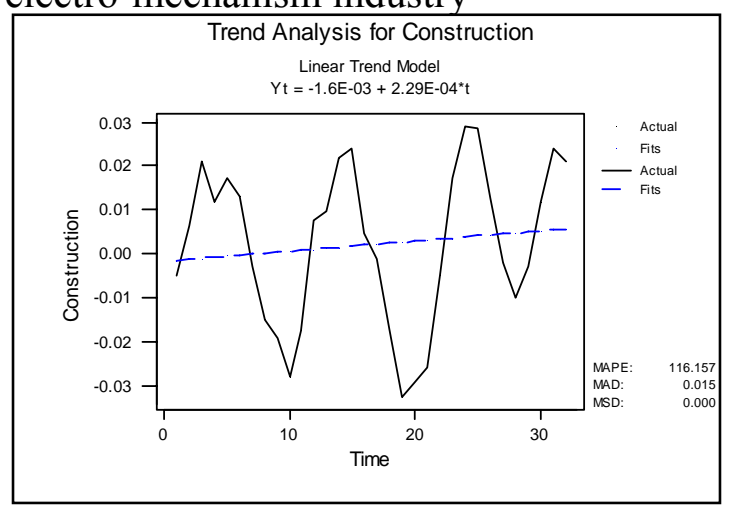

Figure A2-12 state's change rate of constrction industry 
Table A2-1. Normality tests for growth rate of state proxy

\begin{tabular}{|c|c|c|}
\hline \multicolumn{3}{|c|}{ Parameters' estimation of stochastic industrial economic state model } \\
\hline Industry & Proxy & Normality test \\
\hline Steel and metal & Change rate of Shipment Index-Basic Metal & 5.84 \\
\hline $\begin{array}{l}\text { Transportation } \\
\text { equipments }\end{array}$ & $\begin{array}{l}\text { Change rate of Shipment Value- } \\
\text { Transportation Equipment }\end{array}$ & 0.32 \\
\hline Plastics & $\begin{array}{l}\text { Change rate of Export order } \\
\text {-Rubber and Plastic }\end{array}$ & 1.61 \\
\hline Cement & Change rate of Manufacturing Sales & 1.63 \\
\hline Glass and ceramics & $\begin{array}{l}\text { Change rate of Shipment Value-Non-Metal } \\
\text { Miner }\end{array}$ & 1.67 \\
\hline $\begin{array}{l}\text { Information and } \\
\text { electronics }\end{array}$ & $\begin{array}{l}\text { Change rate of Export order-Information and } \\
\text { Communication }\end{array}$ & $11.46^{*}$ \\
\hline $\begin{array}{l}\text { Information and } \\
\text { electronics }\end{array}$ & $\begin{array}{l}\text { Change rate of Shipment Index-Electronic } \\
\text { Component }\end{array}$ & 7.77 \\
\hline $\begin{array}{l}\text { Information and } \\
\text { electronics }\end{array}$ & Change rate of Monitoring Indicator Score & 1.3 \\
\hline $\begin{array}{l}\text { Tourism and } \\
\text { department }\end{array}$ & Change rate of Monitoring Indicator Score & 0.86 \\
\hline Foods & Change rate of Monitoring Indicator Score & 1.91 \\
\hline Wire and cable & Change rate of Monitoring Indicator Score & 0.84 \\
\hline Electro-mechanism & Change rate of Manufacturing Profits Ratio & 1.32 \\
\hline Textile and fiber & Change rate of Shipment Value of Textile & 2.02 \\
\hline Textile and fiber & Change rate of Monitoring Indicator Score & 1.21 \\
\hline Construction & Change rate of GDP & 3.07 \\
\hline Construction & Change rate of Leading Index & 3.83 \\
\hline \multicolumn{3}{|c|}{$\begin{array}{l}\text { *: Significantly reject the null hypothesis of Normality when } \alpha=0.01 \text {. } \\
\text { Note: } \\
\text { 1. In this study, we use Goodness of Fit test (chi-square statistics) to examine liquidity balance } \\
\text { per unit asset's actual distribution. } \\
\text { 2. Since one state proxy appropriate for firms with dissimilar period may have several } \\
\text { chi-square statistics, for the sake of simplification, we only show the largest one to present } \\
\text { its normality. }\end{array}$} \\
\hline
\end{tabular}




\section{Appendix III. The method to estimate parameters of state-dependent stochastic}

\section{liquidity balance model}

In this study, our stochastic liquidity balance model can be showed as equation (A3-1):

$$
d\left(L B / A_{t}\right)=a(t) \cdot\left[b(t)-L B / A_{t-1}\right] \cdot d t+\sigma(t) \cdot d z, \quad d z=\varepsilon \sqrt{d t}, \quad \varepsilon \sim N(0,1) \quad(\mathrm{A} 3-1)
$$

where,

$d\left(\mathrm{LB} / \mathrm{A}_{t}\right): \mathrm{LB} / \mathrm{A}$ 's term variation (or instantaneous changes in continuous time)

$a(t): \mathrm{LB} / \mathrm{A}$ 's mean-reversion speed.

$b(t): \mathrm{LB} / \mathrm{A}$ ’s long-term average level

$\sigma(t)$ : standard deviation of LB/A's term variation, namely $\sqrt{\operatorname{Var}\left(d\left(L B / A_{t}\right)\right)}$.

To adjust the parameters $(\mathrm{b}(\mathrm{t}), \sigma(\mathrm{t}))$, we first estimate an initial parameter values through AR(1) method (Chen, 1996) and then employ Maximum likelihood estimation from historical data.

Let $\mathrm{LB} / \mathrm{A}$ denote the natural value of liquidity balance per unit asset and $\omega$ indicate the industrial economic state factor. The relationship between LB/A and industrial economic state factor $(\omega)$ by the regression is shown in equation (A4-2):

$$
L B / A(t)=\alpha_{0}+\alpha_{1} \cdot \omega(t)
$$

We can then make time-varying adjustments on the long-term average of LB/A $(b(t))$ based on the future LB/A's growth rate relative to the initial value of $b$. According to equation (A3-3), we can further transfer the future LB/A's growth rate to the future industrial economic state indictor's growth rate:

$$
\begin{aligned}
b(t) & =b \cdot\left(1+\left[\left(\frac{L B / A(t)}{\bar{C}_{\text {long-term }}}\right)^{\frac{1}{t}}-1\right)\right. \\
& =b \cdot\left(1+\left[\left(\frac{\alpha_{0}+\alpha_{1} \cdot \omega(t)}{b}\right)^{\frac{1}{t}}-1\right]\right)
\end{aligned}
$$

In equation (A3-3), notice that the parameter's, b, time-varying adjustment is quarter-based so we use geometric mean method.

To adjust the variances of LB/A $(\sigma)$, first, we difference on the both sides of equation (A3-2) and then take variances as shown in equation (A3-4) and (A3-5).

$$
L B / A(t)=\alpha_{1} \cdot \Delta \omega(t)
$$




$$
\operatorname{Var}(\Delta L B / A(t))=\alpha_{1}^{2} \cdot \operatorname{Var}(\Delta \omega(t)) \Rightarrow \sigma_{\Delta\left(L B / A_{t}\right)}=\left|\alpha_{1}\right| \cdot \sigma_{\Delta\left(\omega_{t}\right)}
$$

According to equation (A3-4) and (A3-5), we can obtain equation (A3-6) and (A3-7) When $\alpha_{1}$ is positive or negative respectively.

$$
\begin{gathered}
\alpha_{1}=\frac{\Delta L B / A(t)}{\Delta \omega(t)}=\frac{\sigma_{\Delta\left(L B / A_{t}\right)}}{\sigma_{\Delta\left(\omega_{t}\right)}} \\
-\alpha_{1}=-\frac{\Delta L B / A(t)}{\Delta \omega(t)}=\frac{\sigma_{\Delta\left(L B / A_{t}\right)}}{\sigma_{\Delta\left(\omega_{t}\right)}}
\end{gathered}
$$

We can therefore conclude that the size of "effect on the changes of $\Delta L B / A(t)$ caused by the changes of $\Delta \omega(t)$ " (called $A$ event) will be the same with the size of "effect on the $\sigma_{\Delta\left(L B / A_{t}\right)}$ caused by the changes of $\sigma_{\Delta\left(\omega_{t}\right)}$ "'(called $B$ event) when industrial economic state changes in the future.

From equations (A3-6) and (A3-7), we know that $\sigma_{\Delta\left(L B / A_{t}\right)}$ is a function of $\sigma_{\Delta\left(\omega_{t}\right)}$ and $\Delta L B / A(t)$ is a function of $\Delta \omega(t)$. And both two functions are related to the same base, namely $\alpha_{1}$, which is the regressive coefficient in $\Delta L B / A(t)=\alpha_{1} \cdot \Delta \omega(t)$. Therefore according to the concept of varying coefficient model, the effects on A event and B event will be the same by $\alpha_{1}$ when the industrial economic state changes in the future $\left(\Delta \omega(t), \sigma_{\Delta\left(\omega_{t}\right)}\right)$. As a result, we can make adjustments on the variances of cash flow model $(\sigma)$ by using $A$ event instead of $B$ event. In the following, we will infer the A event's effect firstly, then apply the result to $B$ event and at last we can conclude the adjustment methods of $(\sigma)$ :

\section{Inferences:}

When the industrial economic state indictor is $\omega(t-1)$ in the future time $t-1$, we can obtain the adjustment effect reflecting in the change in the long-term average LB/A (b) according to equation (A4-3):

$$
\frac{b(t-1)-b}{b}=\left(\frac{\alpha_{0}+\alpha_{1} \cdot \omega(t-1)}{b}\right)^{\frac{1}{t-1}}-1
$$

When the industrial economic state factor is $\omega(t)$ in the future time $t$, we can get the adjustment effect of reflecting on the long-term average LB/A (b) according to equation (A4-3):

$$
\frac{b(t)-b}{b}=\left(\frac{\alpha_{0}+\alpha_{1} \cdot \omega(t)}{b}\right)^{\frac{1}{t}}-1
$$

We let equation (A3-9) minus equation (A3-8) and then get the influencing amount of $A$ 
event:

$$
b \cdot\left(\left(\frac{\alpha_{0}+\alpha_{1} \cdot \omega(t)}{b}\right)^{\frac{1}{t}}-\left(\frac{\alpha_{0}+\alpha_{1} \cdot \omega(t-1)}{b}\right)^{\frac{1}{t-1}}\right)
$$

Therefore the percentage influencing size of $A$ event from time $\mathrm{t}-1$ to time $\mathrm{t}$ can be shown as the equation (A4-11):

$$
\left(\frac{\alpha_{0}+\alpha_{1} \cdot \omega(t)}{b}\right)^{\frac{1}{t}}-\left(\frac{\alpha_{0}+\alpha_{1} \cdot \omega(t-1)}{b}\right)^{\frac{1}{t-1}}
$$

Because the influencing effects for A event and B event are the same when applying in the parameter's, $\sigma$, adjustments. We therefore illustrate the time-varying $\sigma$ according to equation (A3-12) in the following.

$$
\sigma_{L B / A}(t)=\sigma_{L B / A} \cdot\left(1+\left(\frac{\alpha_{0}+\alpha_{1} \cdot \omega(t)}{b}\right)^{\frac{1}{t}}-\left(\frac{\alpha_{0}+\alpha_{1} \cdot \omega(t-1)}{b}\right)^{\frac{1}{t-1}}\right)
$$

In equation (A3-12), $\mathrm{t}$ must be larger than one. 
Appendix IV. Parameter estimation of liquidity balance model by MLE optimization

Table A4-1. The Parameters' estimation of liquidity balance model

\begin{tabular}{|c|c|c|c|c|c|c|c|}
\hline \multicolumn{8}{|c|}{ Parameters Estimation for Liquidity balance Model } \\
\hline Item & Ticker & $a$ & $b$ & $\sigma$ & Fval. & $\alpha_{0}$ & $\alpha_{1}$ \\
\hline \multicolumn{8}{|c|}{ I. Steel and metal Industry } \\
\hline \multirow[t]{2}{*}{1} & $\mathrm{CSC}$ & 0.0539 & 0.1757 & 0.0259 & -70.929 & -0.5070 & 0.5600 \\
\hline & & $(0.0013)$ & $(0.0010)$ & $(0.0002)$ & & & \\
\hline \multirow[t]{2}{*}{2} & Ornatube & 1.8092 & 0.0269 & 0.0526 & -69.459 & 0.0226 & 0.0032 \\
\hline & & $(0.1839)$ & $(0.0000)$ & $(0.0028)$ & & & \\
\hline \multicolumn{8}{|c|}{ II. Transportation Equipment Industry } \\
\hline \multirow[t]{2}{*}{3} & Yulon & 0.7170 & 0.1606 & 0.0403 & -66.966 & -0.0330 & 0.0480 \\
\hline & & $(0.0266)$ & $(0.0001)$ & $(0.0008)$ & & & \\
\hline \multicolumn{8}{|c|}{ III. Plastics Industry } \\
\hline \multirow[t]{2}{*}{4} & FCFC & 0.1672 & 0.0614 & 0.0254 & -59.695 & -0.0900 & 0.0180 \\
\hline & & $(0.0087)$ & $(0.0010)$ & $(0.0003)$ & & & \\
\hline \multirow[t]{2}{*}{5} & FPC & 0.2371 & 0.0697 & 0.0327 & -66.893 & -0.0430 & 0.0110 \\
\hline & & $(0.0106)$ & $(0.0007)$ & $(0.0004)$ & & & \\
\hline \multirow[t]{2}{*}{6} & NPC & 0.4543 & 0.0343 & 0.0147 & -95.764 & -0.0760 & 0.0190 \\
\hline & & $(0.0255)$ & $(0.0002)$ & $(0.0003)$ & & & \\
\hline \multicolumn{8}{|c|}{ IV. Cement Industry } \\
\hline \multirow[t]{2}{*}{7} & ACC & 0.7905 & 0.0379 & 0.0171 & -95.272 & -0.0180 & 0.0010 \\
\hline & & $(0.0253)$ & $(0.0000)$ & $(0.0003)$ & & & \\
\hline \multicolumn{8}{|c|}{ V. Glass and ceramics Industry } \\
\hline \multirow[t]{2}{*}{8} & KPT & 0.4739 & 0.0384 & 0.0600 & -51.02 & -0.5990 & 0.3640 \\
\hline & & $(0.0113)$ & $(0.0000)$ & $(0.0008)$ & & & \\
\hline \multirow[t]{2}{*}{9} & Must & 0.1791 & 0.0520 & 0.0389 & -58.87 & -0.5460 & 0.3400 \\
\hline & & $(0.0032)$ & $(0.0001)$ & $(0.0004)$ & & & \\
\hline \multicolumn{8}{|c|}{ VI. Information and electronics Industry } \\
\hline \multirow[t]{2}{*}{10} & TSMC & 0.0966 & 0.2262 & 0.0335 & -63.600 & -0.0100 & 0.1770 \\
\hline & & $(0.0024)$ & $(0.0007)$ & $(0.0003)$ & & & \\
\hline \multirow[t]{2}{*}{11} & UMC & 0.4207 & 0.2339 & 0.0603 & -50.082 & 0.2170 & 0.0130 \\
\hline & & $(0.0096)$ & $(0.0001)$ & $(0.0008)$ & & & \\
\hline \multirow[t]{2}{*}{12} & Hon Hai & 0.9408 & 0.0658 & 0.0513 & -61.966 & -0.0140 & 0.0040 \\
\hline & & $(0.0356)$ & $(0.0000)$ & $(0.0011)$ & & & \\
\hline 13 & Compal & 0.6700 & 0.2825 & 0.1272 & -29.629 & 0.2090 & 0.3050 \\
\hline
\end{tabular}




\begin{tabular}{|c|c|c|c|c|c|c|c|}
\hline & & $(0.0191)$ & $(0.0000)$ & $(0.0020)$ & & & \\
\hline \multirow[t]{2}{*}{14} & Yageo & 0.3919 & 0.0765 & 0.0656 & -46.989 & -0.0090 & 0.3940 \\
\hline & & $(0.0087)$ & $(0.0001)$ & $(0.0008)$ & & & \\
\hline \multirow[t]{2}{*}{15} & $\mathrm{CMC}$ & 0.7083 & 0.0926 & 0.0502 & -59.858 & -0.0080 & 0.0050 \\
\hline & & $(0.0210)$ & $(0.0000)$ & $(0.0008)$ & & & \\
\hline \multirow[t]{2}{*}{16} & Benq & 0.5652 & 0.0832 & 0.0660 & -49.244 & 0.0220 & 0.2690 \\
\hline & & $(0.0146)$ & $(0.0000)$ & $(0.0010)$ & & & \\
\hline \multirow[t]{2}{*}{17} & ADI & 1.3279 & 0.0406 & 0.0572 & -62.574 & 0.0370 & 0.0250 \\
\hline & & $(0.0756)$ & $(0.0000)$ & $(0.0018)$ & & & \\
\hline \multirow{3}{*}{18} & Mega & 0.1497 & 0.0719 & 0.0309 & -67124 & -00370 & 00080 \\
\hline & & & & & & & \\
\hline & & $(0.0027)$ & $\begin{array}{l}(0.0001) \\
\end{array}$ & $(0.0003)$ & & & \\
\hline \multicolumn{8}{|c|}{ VII. Tourism and department Industry } \\
\hline \multirow[t]{2}{*}{19} & Imperial & 0.5434 & 0.0294 & 0.0306 & -73.554 & -0.0200 & 0.0020 \\
\hline & & $(0.0189)$ & $(0.0001)$ & $(0.0005)$ & & & \\
\hline \multirow[t]{2}{*}{20} & TID & 1.4430 & 0.0213 & 0.0345 & -58.870 & -0.0020 & 0.0010 \\
\hline & & $(0.0946)$ & $(0.0000)$ & $(0.0012)$ & & & \\
\hline \multicolumn{8}{|c|}{ VIII. Foods Industry } \\
\hline \multirow{3}{*}{21} & Chou & 2.4364 & 0.0297 & 0.0719 & -63.943 & 0.0250 & 0.0030 \\
\hline & Cnin & $0<010$ & $(0 \Omega \cap \circ)$ & 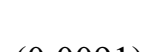 & & & \\
\hline & & $(0.6016)$ & $(0.0001)$ & $(0.0091)$ & & & \\
\hline \multirow[t]{2}{*}{22} & Yuan Yi & 0.3096 & 0.1373 & 0.0716 & -42.954 & 0.0340 & 0.0460 \\
\hline & & $(0.0066)$ & $(0.0002)$ & $(0.0008)$ & & & \\
\hline \multirow[t]{2}{*}{23} & TI & 2.5128 & 0.0162 & 0.0795 & -61.223 & 0.0050 & 0.0050 \\
\hline & & $(0.6517)$ & $(0.0000)$ & $(0.0106)$ & & & \\
\hline \multirow[t]{2}{*}{24} & SJI & 1.2947 & 0.0213 & 0.0344 & -78.538 & -0.0080 & 0.0140 \\
\hline & & $(0.0717)$ & $(0.0000)$ & $(0.0010)$ & & & \\
\hline \multicolumn{8}{|c|}{ IX. Wire and cable. Industry } \\
\hline \multirow[t]{2}{*}{25} & PEWC & 0.1311 & 0.1331 & 0.0382 & -60.042 & 0.0400 & 0.0520 \\
\hline & & $(0.0032)$ & $(0.0006)$ & $(0.0004)$ & & & \\
\hline \multicolumn{8}{|c|}{ X. Electro-mechanism Industry } \\
\hline \multirow[t]{2}{*}{26} & Ensure & 0.6965 & 0.0589 & 0.0586 & -54.765 & 0.0010 & 0.0100 \\
\hline & & $(0.0204)$ & $(0.0000)$ & $(0.0010)$ & & & \\
\hline \multicolumn{8}{|c|}{ XI. Textile and fiber Industry } \\
\hline \multirow[t]{2}{*}{27} & Hualon & 0.8616 & 0.0130 & 0.0162 & -97.932 & -0.0030 & 0.0010 \\
\hline & & $(0.0323)$ & $(0.0000)$ & & & & \\
\hline
\end{tabular}




\begin{tabular}{|c|c|c|c|c|c|c|c|}
\hline 28 & CST & $\begin{array}{c}0.7359 \\
(0.0252)\end{array}$ & $\begin{array}{c}0.0153 \\
(0.0000)\end{array}$ & $\begin{array}{c}0.0150 \\
(0.0003)\end{array}$ & -98.759 & -0.0070 & 0.0010 \\
\hline 29 & Maxim & $\begin{array}{c}1.3257 \\
(0.0755)\end{array}$ & $\begin{array}{c}0.0265 \\
(0.0000)\end{array}$ & $\begin{array}{c}0.0816 \\
(0.0025)\end{array}$ & -51.161 & -0.1260 & 0.0570 \\
\hline 30 & $\begin{array}{c}\mathrm{Yu} \\
\text { Foong }\end{array}$ & $\begin{array}{c}0.1648 \\
(0.0035)\end{array}$ & $\begin{array}{c}0.1555 \\
(0.0005)\end{array}$ & $\begin{array}{c}0.0591 \\
(0.0006)\end{array}$ & -46.688 & 0.1020 & 0.0030 \\
\hline 31 & Shin Yih & $\begin{array}{c}0.2372 \\
(0.0046)\end{array}$ & $\begin{array}{c}0.1755 \\
(0.0003)\end{array}$ & $\begin{array}{c}0.1125 \\
(0.0012)\end{array}$ & -27.335 & -0.7550 & 0.3480 \\
\hline \multicolumn{8}{|c|}{ XII. Construction Industry } \\
\hline 32 & CRE & $\begin{array}{c}0.0921 \\
(0.0021)\end{array}$ & $\begin{array}{c}0.1744 \\
(0.0010)\end{array}$ & $\begin{array}{c}0.0537 \\
(0.0005)\end{array}$ & -48.362 & -1.1030 & 0.4900 \\
\hline 33 & $\begin{array}{l}\text { Long } \\
\text { Bon }\end{array}$ & $\begin{array}{c}2.4178 \\
(0.5575)\end{array}$ & $\begin{array}{c}0.0255 \\
(0.0000)\end{array}$ & $\begin{array}{c}0.0480 \\
(0.0057)\end{array}$ & -76.765 & -0.2310 & 0.2530 \\
\hline 34 & $\begin{array}{c}\text { Pao } \\
\text { Shiang }\end{array}$ & $\begin{array}{c}0.2975 \\
(0.0063)\end{array}$ & $\begin{array}{c}0.0569 \\
(0.0002)\end{array}$ & $\begin{array}{c}0.0681 \\
(0.00080\end{array}$ & -44.3310 & -0.0920 & 0.0780 \\
\hline 35 & BaoChen & $\begin{array}{c}2.1398 \\
(0.3365)\end{array}$ & $\begin{array}{c}0.0046 \\
(0.0001)\end{array}$ & $\begin{array}{c}0.0931 \\
(0.0076)\end{array}$ & -53.706 & -0.0060 & 0.0060 \\
\hline 36 & $\begin{array}{c}\text { Lin San } \\
\text { Hao }\end{array}$ & $\begin{array}{c}0.3412 \\
(0.0073)\end{array}$ & $\begin{array}{c}0.0495 \\
(0.0001)\end{array}$ & $\begin{array}{c}0.0582 \\
(0.0007)\end{array}$ & -50.059 & -0.1880 & 0.2330 \\
\hline 37 & $\begin{array}{c}\text { Pacific } \\
\text { Construct } \\
\text { ion }\end{array}$ & $\begin{array}{c}1.2764 \\
(0.0713)\end{array}$ & $\begin{array}{c}0.0128 \\
(0.0000)\end{array}$ & $\begin{array}{c}0.0129 \\
(0.0004)\end{array}$ & -109.81 & 0.0110 & 0.0010 \\
\hline $\begin{array}{l}1 . \mathrm{Th} \\
2 . \mathrm{In} \\
\text { optin } \\
\text { mear }\end{array}$ & $\begin{array}{l}\text { ie in ( ) is } \\
\text { udy, we } \\
\text { on techr } \\
\text { ting stoc } \\
\text { ds for the }\end{array}$ & $\begin{array}{l}\text { andard de } \\
\text { maximu } \\
\text { ue to } \\
\text { tic mode } \\
\text { aximum }\end{array}$ & $\begin{array}{l}\text { tion of } \\
\text { ikelihoo } \\
\text { lement } \\
\text { de of lik }\end{array}$ & $\begin{array}{l}\text { l's paran } \\
\text { mation } \\
\text { ameters } \\
\text { od funct }\end{array}$ & E) methoc & $\begin{array}{r}\text { netic a } \\
\text { conc }\end{array}$ & $\begin{array}{l}\text { thm, and } \\
\text { ing on }\end{array}$ \\
\hline
\end{tabular}


Appendix V. Parameter estimation of stochastic industrial economic state model by MLE optimization

Table A5-1. Parameters' estimation of stochastic industrial economic state model

\begin{tabular}{|c|c|c|c|c|c|}
\hline \multicolumn{6}{|c|}{ Parameters' estimation of stochastic industrial economic state model } \\
\hline Industry & Simulation target & $a_{\eta}$ & $b_{\eta}$ & $\sigma_{\eta}$ & Fval. \\
\hline \multirow{2}{*}{ Steel and metal } & Change rate of Shipment & 0.5637 & 0.0088 & 0.0273 & -77.503 \\
\hline & Index-Basic Metal & $(0.0145)$ & $(0.0000)$ & $(0.0004)$ & \\
\hline \multirow{2}{*}{$\begin{array}{c}\text { Transportation } \\
\text { equipments }\end{array}$} & Change rate of Shipment Value- & 0.3678 & 0.0086 & 0.0329 & -68.711 \\
\hline & Transportation Equipment & $(0.0078)$ & $(0.0000)$ & $(0.0004)$ & \\
\hline \multirow{2}{*}{ Plastics } & Change rate of Export order & 0.3774 & 0.0200 & 0.0404 & -50.469 \\
\hline & -Rubber and Plastic & $(0.0088)$ & $(0.0001)$ & $(0.0005)$ & \\
\hline \multirow{2}{*}{ Cement } & Change rate of Manufacturing & 0.3925 & 0.0145 & 0.0287 & -73.497 \\
\hline & Sales & $(0.0093)$ & $(0.0001)$ & $(0.0004)$ & \\
\hline \multirow{2}{*}{ Glass and ceramics } & Change rate of Shipment & 0.5298 & 0.0018 & 0.0226 & -83.083 \\
\hline & Value-Non-Metal Miner & $(0.0136)$ & $(0.0000)$ & $(0.0003)$ & \\
\hline \multirow{2}{*}{$\begin{array}{l}\text { Information and } \\
\text { electronics }\end{array}$} & Change rate of Export & 0.7471 & 0.0250 & 0.0465 & -62.781 \\
\hline & $\begin{array}{l}\text { order-Information and } \\
\text { Communication }\end{array}$ & $(0.0230)$ & $(0.0000)$ & $(0.0008)$ & \\
\hline \multirow{2}{*}{$\begin{array}{l}\text { Information and } \\
\text { electronics }\end{array}$} & Change rate of Shipment & 0.3428 & 0.0339 & 0.0381 & -63.647 \\
\hline & Index-Electronic Component & $(0.0071)$ & $(0.0000)$ & $(0.0004)$ & \\
\hline \multirow{2}{*}{$\begin{array}{c}\text { Information and } \\
\text { electronics }\end{array}$} & Change rate of Monitoring & 0.3896 & 0.0297 & 0.1257 & -26.130 \\
\hline & Indicator Score & $(0.0084)$ & $(0.0000)$ & $(0.0015)$ & \\
\hline \multirow{2}{*}{$\begin{array}{c}\text { Tourism and } \\
\text { department }\end{array}$} & Change rate of Monitoring & 0.3731 & 0.0128 & 0.0899 & -36.629 \\
\hline & Indicator Score & $(0.0096)$ & $(0.0004)$ & $(0.0011)$ & \\
\hline \multirow{2}{*}{ Foods } & Change rate of Monitoring & 0.4589 & 0.0008 & 0.1014 & -34.033 \\
\hline & Indicator Score & $(0.0113)$ & $(0.0002)$ & $(0.0013)$ & \\
\hline \multirow{2}{*}{ Wire and cable } & Change rate of Monitoring & 0.4171 & -0.0156 & 0.1144 & -29.561 \\
\hline & Indicator Score & $(0.0093)$ & $(0.0000)$ & $(0.0014)$ & \\
\hline \multirow{2}{*}{ Electro-mechanism } & Change rate of Manufacturing & 0.3685 & -0.0056 & 0.0191 & -86.061 \\
\hline & Profits Ratio & $(0.0090)$ & $(0.0001)$ & $(0.0002)$ & \\
\hline \multirow{2}{*}{ Textile and fiber } & Change rate of Shipment Value of & 0.5012 & 0.0054 & 0.0233 & -81.694 \\
\hline & Textile & $(0.0124)$ & $(0.0000)$ & $(0.0003)$ & \\
\hline \multirow{2}{*}{ Textile and fiber } & Change rate of Monitoring & 0.3980 & 0.0056 & 0.0909 & -36.629 \\
\hline & Indicator Score & $(0.0087)$ & $(0.0000)$ & $(0.0011)$ & \\
\hline
\end{tabular}




\begin{tabular}{|cccccc|}
\hline \multirow{2}{*}{ Construction } & Change rate of GDP & $\begin{array}{c}0.0794 \\
(0.0020)\end{array}$ & $\begin{array}{c}0.0194 \\
(0.0001)\end{array}$ & $\begin{array}{c}0.0022 \\
(0.0000)\end{array}$ & -150.800 \\
\hline \multirow{2}{*}{ Construction } & Change rate of Leading Index & $\begin{array}{c}0.2868 \\
0.0039\end{array}$ & 0.0132 & -96.613 \\
& & $(0.0060)$ & $(0.0000)$ & $(0.0001)$ & \\
\hline \hline
\end{tabular}

1. The value in ( ) is standard deviation of model's parameter.

2. In this study, we use maximum likelihood estimation (MLE) method, genetic algorithm, and optimization technique to implement parameters estimation for conditioning on mean-reverting stochastic model.

3. Since one state proxy appropriate for firms with dissimilar period may have several parameters' estimate, for the sake of simplification, here we show is the same as tableA2-1. 


\section{Appendix VI. Empirical results of liquidity balance model}

The detailed empirical credit analyses results are illustrated in table A6-1. The fourth column of table A6-1 presents probability of insolvency calculated by our liquidity balance model (denoted as "model's PIS") in one year. The fifth column shows expected liquidity deficiency of each sample firm (denoted as “model's ELD") in the coming year. The sixth column demonstrates each firm's theoretical long-term rating and its corresponding short-term rating (denoted as "model's rating") by comparing model's PIS with the one-year default rates curve in American market, and then obtaining the firm's theoretical short-term rating by utilizing the correlation of long- and short-term ratings ${ }^{21}$ and historical transformation of rating firms on TRC website.

Table A6-1. Empirical results of liquidity balance model

\begin{tabular}{|c|c|c|c|c|c|c|}
\hline \multicolumn{7}{|c|}{$\begin{array}{l}\text { Empirical results of liquidity balance model for companies } \\
\text { with and without ratings }\end{array}$} \\
\hline Item & Ticker & Rating Date & $\begin{array}{l}\text { Model's PIS } \\
\text { (One-Year) }\end{array}$ & $\begin{array}{l}\text { Model's ELD } \\
\text { (One-Year) }\end{array}$ & $\begin{array}{c}\text { Model's Rating } \\
\text { (LT / ST) }\end{array}$ & $\begin{array}{c}\text { Actual Rating } \\
\text { (LT / ST) }\end{array}$ \\
\hline \multicolumn{7}{|c|}{ I. Steel and metal Industry } \\
\hline 1 & $\mathrm{CSC}^{*}$ & $2004 / 10 / 12$ & $0.00 \%$ & $0.0000 \%$ & AAA/A-1 & AAA/A-1 \\
\hline 2 & Ornatube & NA & $17.27 \%$ & $0.2553 \%$ & $\mathrm{BB}-/ \mathrm{B}$ & NA \\
\hline \multicolumn{7}{|c|}{ II. Transportation Equipment Industry } \\
\hline 3 & Yulon*** & $2004 / 02 / 25$ & $0.00 \%$ & $0.0000 \%$ & AAA/A-1 & $\mathrm{A} / \mathrm{A}-2$ \\
\hline \multicolumn{7}{|c|}{ III. Plastics Industry } \\
\hline 4 & FCFC* & $2005 / 01 / 06$ & $0.29 \%$ & $0.0026 \%$ & $\mathrm{~A}+/ \mathrm{A}-1$ & AA-/A-1 \\
\hline 5 & FPC* & $2005 / 01 / 06$ & $0.29 \%$ & $0.0040 \%$ & $\mathrm{~A}+/ \mathrm{A}-1$ & AA-/A-1 \\
\hline 6 & $\mathrm{NPC}^{* *}$ & $2005 / 01 / 06$ & $0.37 \%$ & $0.0019 \%$ & $\mathrm{~A} / \mathrm{A}-1$ or $\mathrm{A}-2$ & AA-/A-1 \\
\hline \multicolumn{7}{|c|}{ IV. Cement Industry } \\
\hline 7 & $\mathrm{ACC}^{* *}$ & $2004 / 12 / 22$ & $0.35 \%$ & $0.0017 \%$ & $\mathrm{~A} / \mathrm{A}-1$ or $\mathrm{A}-2$ & $\mathrm{~A} / \mathrm{A}-2$ \\
\hline \multicolumn{7}{|c|}{ V. Glass and ceramics Industry } \\
\hline 8 & KPT & NA & $48.90 \%$ & $4.3954 \%$ & $\mathrm{~B}-/ \mathrm{C}$ & NA \\
\hline
\end{tabular}

21 The correlation of long- and short-term ratings is in the following: For the ratings higher than $\mathrm{A}+$, their short-term ratings will be equivalent to $\mathrm{A}-1+$; for the ratings between $\mathrm{A}+$ and $\mathrm{A}-$, their short-term ratings will be equivalent to A-1; for the ratings between $\mathrm{A}-$ and $\mathrm{BBB}$, their short-term ratings will be equivalent to A-2; for the ratings between $\mathrm{BBB}$ and $\mathrm{BBB}-$, their short-term ratings will be equivalent to $\mathrm{A}-3$; for the ratings between $\mathrm{BB}+$ and $\mathrm{BB}-$, their short-term ratings will be equivalent to $\mathrm{B}$; for the ratings between $\mathrm{B}+$ and $\mathrm{C}$, their short-term ratings will be equivalent to $\mathrm{C}$; and so on. (from the S\&P's rating tables) 


\begin{tabular}{|c|c|c|c|c|c|c|}
\hline 9 & Must & NA & $26.49 \%$ & $0.7741 \%$ & $\mathrm{~B}+/ \mathrm{C}$ & NA \\
\hline \multicolumn{7}{|c|}{ VI. Information and electronics Industry } \\
\hline 10 & TSMC* & $2004 / 06 / 07$ & $0.00 \%$ & $0.0000 \%$ & $\mathrm{AAA} / \mathrm{A}-1$ & $\mathrm{AAA} / \mathrm{A}-1$ \\
\hline 11 & UMC* & $2004 / 06 / 07$ & $0.03 \%$ & $0.0005 \%$ & $\mathrm{AA}+/ \mathrm{A}-1$ & AA/A-1 \\
\hline 12 & Hon Hai $* * * *$ & $2005 / 04 / 11$ & $3.61 \%$ & $0.0680 \%$ & BBB-/A-3 & $\mathrm{AA} / \mathrm{A}-1$ \\
\hline 13 & Compal** & $2004 / 08 / 31$ & $0.37 \%$ & $0.0128 \%$ & $\mathrm{~A} / \mathrm{A}-1$ or $\mathrm{A}-2$ & $\mathrm{~A}+/ \mathrm{A}-1$ \\
\hline 14 & Yageo* & $2005 / 02 / 24$ & $17.43 \%$ & $0.7885 \%$ & BB-/B & $\mathrm{BB}+/ \mathrm{B}$ \\
\hline 15 & $\mathrm{CMC}^{* *}$ & $2004 / 07 / 12$ & $1.50 \%$ & $0.0276 \%$ & $\begin{array}{c}\mathrm{BBB} / \mathrm{A}-2 \text { or } \\
\mathrm{A}-3\end{array}$ & $\mathrm{BBB} / \mathrm{A}-3$ \\
\hline 16 & Benq**** & $2004 / 06 / 10$ & $9.68 \%$ & $0.3055 \%$ & $\mathrm{BB}-/ \mathrm{B}$ & $\mathrm{A} / \mathrm{A}-2$ \\
\hline 17 & ADI & NA & $11.84 \%$ & $0.2006 \%$ & BB-/B & NA \\
\hline 18 & $\begin{array}{l}\text { Mega } \\
\text { media }\end{array}$ & NA & $17.15 \%$ & $0.5580 \%$ & BB-/B & NA \\
\hline \multicolumn{7}{|c|}{ VII. Tourism and department Industry } \\
\hline 19 & $\begin{array}{c}\text { Imperial } \\
\text { Hotel }\end{array}$ & NA & $70.20 \%$ & $1.8473 \%$ & $\mathrm{CC} / \mathrm{C}$ & NA \\
\hline 20 & TID & NA & $14.34 \%$ & $0.1588 \%$ & BB-/B & NA \\
\hline \multicolumn{7}{|c|}{ VIII. Foods Industry } \\
\hline 21 & Chou Chin & NA & $17.78 \%$ & $0.3219 \%$ & $\mathrm{BB}-/ \mathrm{B}$ & NA \\
\hline 22 & Yuan Yi & NA & $10.38 \%$ & $0.4730 \%$ & BB-/B & NA \\
\hline 23 & $\mathrm{TI}$ & NA & $32.00 \%$ & $0.7798 \%$ & $\mathrm{~B} / \mathrm{C}$ & NA \\
\hline 24 & SJI & NA & $16.56 \%$ & $0.1749 \%$ & BB-/B & NA \\
\hline \multicolumn{7}{|c|}{ IX. Wire and cable. Industry } \\
\hline 25 & PEWC & NA & $13.74 \%$ & $0.3974 \%$ & BB-/B & NA \\
\hline \multicolumn{7}{|c|}{ X. Electro-mechanism Industry } \\
\hline 26 & Ensure & NA & $10.90 \%$ & $0.2492 \%$ & BB-/B & NA \\
\hline \multicolumn{7}{|c|}{ XI. Textile and fiber Industry } \\
\hline 27 & Hualon & NA & $15.43 \%$ & $0.1148 \%$ & BB-/B & NA \\
\hline 28 & CST & NA & $12.15 \%$ & $0.0809 \%$ & BB-/B & NA \\
\hline 29 & Maxim. & NA & $30.22 \%$ & $1.1098 \%$ & $\mathrm{~B} / \mathrm{C}$ & NA \\
\hline 30 & Yu Foong & NA & $17.25 \%$ & $0.8330 \%$ & BB-/B & NA \\
\hline
\end{tabular}




\begin{tabular}{|c|c|c|c|c|c|c|}
\hline 31 & Shin Yih & NA & $19.87 \%$ & $1.6358 \%$ & BB-/B & NA \\
\hline \multicolumn{7}{|c|}{ XII. Construction Industry } \\
\hline 32 & $\mathrm{CRE}^{* * *}$ & $2004 / 12 / 22$ & $0.16 \%$ & $0.0046 \%$ & AA-/A-1 & A-/A-2 \\
\hline 33 & $\begin{array}{c}\text { Long } \\
\text { Bon*** }\end{array}$ & $2005 / 03 / 10$ & $11.91 \%$ & $0.1539 \%$ & $\mathrm{BB}-/ \mathrm{B}$ & $\mathrm{BBB}+/ \mathrm{A}-3$ \\
\hline 34 & Pao Shiang & NA & $33.24 \%$ & $2.2761 \%$ & $\mathrm{~B} / \mathrm{C}$ & NA \\
\hline 35 & Bao-Chen & NA & $45.51 \%$ & $1.9068 \%$ & $\mathrm{~B}-/ \mathrm{C}$ & NA \\
\hline 36 & Lin San Hao & NA & $27.36 \%$ & $1.2366 \%$ & $\mathrm{~B}+/ \mathrm{C}$ & NA \\
\hline 37 & $\begin{array}{c}\text { Pacific } \\
\text { Construction }\end{array}$ & NA & $5.41 \%$ & $0.0185 \%$ & $\mathrm{BB} / \mathrm{B}$ & NA \\
\hline \multicolumn{7}{|c|}{$\begin{array}{l}\text { * : model's rating is consistent with actual rating; } \\
* * \text { : model's rating is either the same or one grade difference with actual rating (there are two } \\
\text { short-term ratings transformed by the same long-term rating); } \\
\text { *** : model's rating is one grade difference with actual rating; } \\
\text { **** : model's rating is at least two grade difference with actual rating. } \\
\text { 1. Each firm's actual rating is acquired from TRC's website. } \\
\text { 2. Model's PIS and ELD are from } 10000 \text { times simulation through "state-dependent stochastic } \\
\text { liquidity balance model" for each sampled firm. And then we can calculate the one-year } \\
\text { probability of insolvency (PIS) and one-year expected liquidity deficiency. (ELD) } \\
\text { 3. Corresponding model's PIS and ELD to American one-year average forward default rates } \\
\text { provided by S\&P (1981 2003) and further we can decide the credit rating for each firm. }\end{array}$} \\
\hline
\end{tabular}

